NORMA LÚCIA DE SOUZA

AVALIAÇÃO DOS EFEITOS DA MOXIDECTINA SOBRE AS CARACTERÍSTICAS REPRODUTIVAS DE TOUROS

Pirassununga-SP

2007 


\section{AVALIAÇÃO DOS EFEITOS DA MOXIDECTINA SOBRE AS CARACTERÍSTICAS REPRODUTIVAS DE TOUROS}

Tese apresentada ao Programa de Pós-Graduação em Reprodução Animal da Faculdade de Medicina Veterinária e Zootecnia da Universidade de São Paulo para obtenção do título de Doutor em Medicina Veterinária

Departamento:

Reprodução Animal

Área de Concentração:

Reprodução Animal

Orientador:

Prof. Dr. Rubens Paes de Arruda

Pirassununga-SP

2007 
Autorizo a reprodução parcial ou total desta obra, para fins acadêmicos, desde que citada a fonte.

DADOS INTERNACIONAIS DE CATALOGAÇÃO-NA-PUBLICAÇÃO

(Biblioteca Virginie Buff D’Ápice da Faculdade de Medicina Veterinária e Zootecnia da Universidade de São Paulo)

T.1843 Souza, Norma Lúcia de

FMVZ Avaliação dos efeitos da moxidectina sobre as características reprodutivas de touros / Norma Lúcia de Souza. - Pirassununga : N. L. Souza, 2007.

$82 \mathrm{f}$. : il.

Tese (doutorado) - Universidade de São Paulo. Faculdade de Medicina Veterinária e Zootecnia. Departamento de Reprodução Animal, 2007.

Programa de Pós-graduação: Reprodução Animal. Área de concentração: Reprodução Animal.

Orientador: Prof. Dr. Rubens Paes de Arruda.

1. Bovinos. 2. Espermatozóides. 3. Anti-helmíntico. I. Título. 


\section{UNIVERSIDADE DE SÃO PAULO Faculdade de Medicina Veterinária e Zootecnia \\ Comissão Bioética}

\section{CERTIFICADO}

Certificamos que o Projeto intitulado "Avaliação dos efeitos da moxidectina sobre as características reprodutivas de touros", protocolado sob o n⿳1060/2007, utilizando 16 (dezesseis) bovinos, sob a responsabilidade do Prof. Dr. Rubens Paes de Arruda, está de acordo com os princípios éticos de experimentação animal da Comissão de Bioética da Faculdade de Medicina Veterinária e Zootecnia da Universidade de São Paulo e foi aprovado "ad referendum".

(We certify that the Research "Effects of the moxidectin on reproductive characteristic of bills", protocol number 1060/2007, utilizing 16 (sixteen) bovines, under the responsibility Prof. Dr. Rubens Paes de Arruda, agree with Ethical Principles in Animal Research adopted by Bioethic Commission of the School of Veterinary Medicine and Zootechny of University of São Paulo and was approved "ad referendum", meeting).

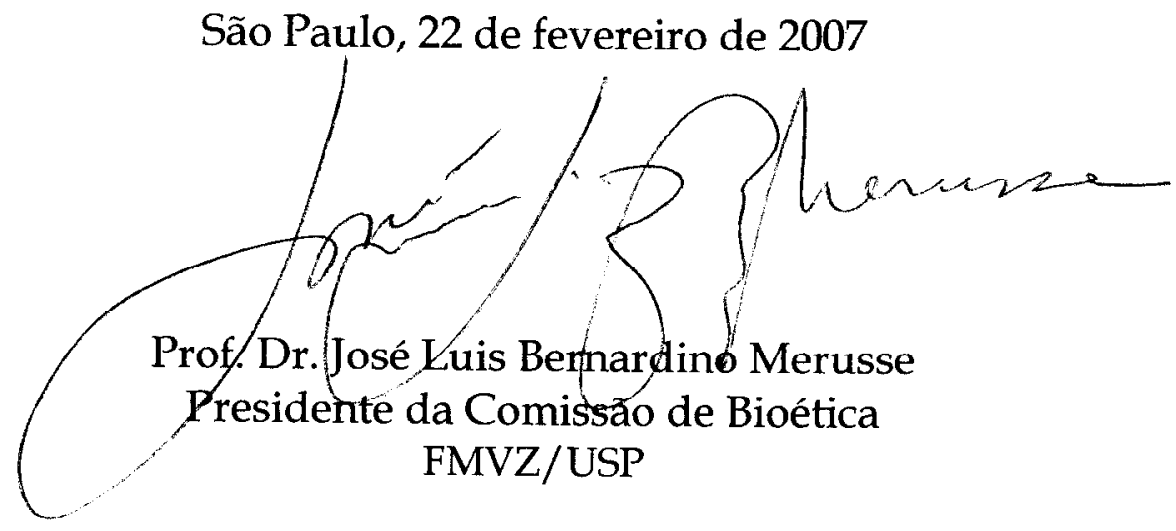




\section{FOLHA DE AVALIAÇÃO}

Nome: SOUZA, Norma Lúcia de

Título: Avaliação dos efeitos da moxidectina sobre as características reprodutivas de touros

Tese apresentada ao Programa de PósGraduação em Reprodução Animal da Faculdade de Medicina Veterinária e Zootecnia da Universidade de São Paulo para obtenção do título de Doutor em Medicina Veterinária.

Data:

1

Banca Examinadora

Prof. Dr.

Assinatura:

Prof. Dr.

Assinatura:

Prof. Dr.

Assinatura:

Prof. Dr.

Assinatura:

Prof. Dr.

Assinatura:
Instituição:

Julgamento:

Instituição:

Julgamento:

Instituição:

Julgamento:

Instituição:

Julgamento:

Instituição:

Julgamento: 


\section{À Maria Heloísa}

"Deus, de vez em quando tem dó de nossa condição e nos envia esses seres inexplicáveis para que experimentemos a alegria do mundo de beleza perfeita."

Rubem Alves 
Aos meus pais Lula e Lucinha

Que realizam todos os dias a mais complexa arte: educar seus filhos para a vida.

Obrigada por ensinar-me a nunca desistir

Obrigada por ensinar-me a arte da paciência e da humildade.

A Anníbal, homem generoso, meu esposo amado, pela felicidade, amor e carinho de todos os dias.

Às minhas irmãs Edna, Alane e Laysa

Pelas horas alegres de cada dia

Por de quando em vez me mostrarem outras formas de encarar as coisas.

Ao meu querido avô "Seu Biu"

O homem mais espetacular que já conheci.

Agradeço a Deus pelo presente que nos deu: O milagre de tê-lo ainda conosco. 
Meus mais profundos agradecimentos

A Deus, Pai Todo Poderoso, por estar comigo em todos os momentos e por todas as maravilhas que tem feito em minha vida.

Ao meu querido mestre e amigo Professor Carlos Peña, por sempre ter acreditado em mim, muitas vezes mais até do que eu mesma.

A André Furugem, por sua fundamental importância na execução deste estudo e na elaboração desta tese e ainda, pelas horas alegres.

Ao colega pós-graduando Luiz Augusto Ferreira Rossa, por ter tornado possível a execução desse experimento.

Aos colegas e amigos da Universidade Federal de Campina Grande, a minha casa, por seu apoio nas dificuldades e, principalmente, por abrirem as portas para que eu pudesse ingressar na carreira docente.

À Juliana Nascimento (Jujú), Cláudia Raphael (Claudinha) e a Karen Peres, por terem me ensinado sobre amizade.

Ao Alexandre Marques (Menininho), porque está sempre no meu coração, como amigo e irmão, e que a distância e o tempo não apaga.

Aos demais colegas da pós-graduação do VRA que participaram da execução deste experimento.

Aos demais colegas do CBRA: Zé Rodrigo, Vanessa Marques, Fernandinho, pela horas alegres de descontração.

Ao Prof. Dr. Renato Campanarut Barnabe, por seu inestimável exemplo de dedicação profissional.

Aos Professores do CBRA, Ed Hoffmann, Aneliese Traldi e Mário Binelli, pelo exemplo de competência e dedicação à profissão.

A Elza, bibliotecária, por seu esforço tão precioso durante a fase final de elaboração da tese.

À Isabel, grande amiga de longa data, por estar sempre disposta a nos auxiliar.

A Harumy, por sua presteza em nos atender sempre que necessário.

Ao Marcio, ao Zé Maria e à Edna, por todo o apoio prestado.

E a todos aqueles que não estão aqui enumerados, por displicência de minha parte, mas que foram e continuam sendo muito importantes na minha caminhada e que de alguma maneira me ajudaram a chegar até aqui. 
Ao Professor Rubens, meu orientador

Não poderia dizer simplesmente obrigado, porque é pouco.

Fica, portanto, registrado o meu reconhecimento por sua grande generosidade.

A minha admiração por seu empenho em prol do crescimento de cada pós-graduando que por ele passa.

Por seu cuidado na execução de tudo o que iremos realizar, por considerar que cada detalhe é fundamental.

Por tudo o que tem me ensinado em todos esses anos.

E, finalmente, por abrir as portas da sua casa, junto com sua família e por conceder-me a honra de sua amizade.

A Eneiva Carla e Cláudia Bertan,

Grandes e preciosas amigas que a vida me deu. Que os anos mostraram que fazem parte da minha família, que se não for pelo sangue, pelos laços do coração. 
"Pouco conhecimento faz com que as criaturas sintamse orgulhosas. Muito conhecimento, que se sintam humildes. É assim que as espigas sem grãos erguem desdenhosamente a cabeça para o céu, enquanto as cheias as baixam para a terra, sua mãe.”

Da Vinci 


\section{RESUMO}

SOUZA, N. L. Avaliação dos efeitos da moxidectina sobre as características reprodutivas de touros. [Evaluation of effects of moxidectin on the reproductive characteristics of the bulls]. 2007. $82 \mathrm{f}$. Tese (Doutorado em Medicina Veterinária) Faculdade de Medicina Veterinária e Zootecnia, Universidade de São Paulo, Pirassununga, 2007.

Os parasitas nematóides afetam homens e animais, causando graves prejuízos à saúde pública e consideráveis perdas econômicas. A disponibilidade de anti-helmínticos de amplo espectro de ação tem auxiliado na redução de um grande número de perdas em decorrência das infestações parasitárias. Foram objetivos deste trabalho avaliar os efeitos do tratamento com moxidectina, na forma de longa-ação (LA), em sua dose terapêutica em touros, sobre a consistência e perímetro testicular, as características físicas (motilidade e vigor) e morfológicas do sêmen e o comportamento sexual. Foram utilizados 12 touros com idade de $48 \pm 10$ meses. Os animais foram alocados em 6 blocos com dois tratamentos. Os animais foram divididos nos grupos: controle $(\mathrm{n}=6)$, no qual cada animal recebeu $5 \mathrm{~mL}$ de solução fisiológica, via subcutânea, na orelha esquerda e grupo tratado $(n=6)$, no qual cada animal recebeu $5 \mathrm{~mL}$ de moxidectina a 10\% via subcutânea, na orelha esquerda. Os animais foram submetidos a exames andrológicos semanais, por um período de até 60 dias após o tratamento, sendo avaliadas as características testiculares (consistência e perímetro) e características seminais (motilidade, vigor e morfologia). Foram realizados testes de libido a cada 15 dias, num total de cinco testes. Os resultados obtidos indicam que não houve diferença significativa $(\mathrm{P}>0,05)$ para a consistência testicular, perímetro testicular, motilidade progressiva, vigor espermático, morfologia espermática e libido entre os touros dos grupos controle e tratado. Esses resultados indicam que o tratamento com moxidectina a $10 \%$ não influencia negativamente as características reprodutivas de touros.

Palavras-chave: Bovinos. Espermatozóides. Anti-helmíntico. 


\begin{abstract}
SOUZA, N. L. Evaluation of effects of moxidectin on the reproductive characteristics of the bulls. [Avaliação dos efeitos da moxidectina sobre as características reprodutivas de touros]. 2007. 82 f. Tese (Doutorado em Medicina Veterinária) Faculdade de Medicina Veterinária e Zootecnia, Universidade de São Paulo, Pirassununga, 2007.

The helminths affect human beings and animals, causing serious damage to public health and considerable economic losses. The availability of anthelminthic of a broad-spectrum has helped reducing a large number of losses due to parasitic infestation. The objectives of this work were to evaluate the effect of the treatment with moxidectin, in Long Action (LA) formulation, in therapeutic doses in bulls, on the testicular consistency and perimeter, physical characteristics (motility and strength) and morphological of the semen and sexual behaviour. Twelve bulls, age $48 \pm 10$ months used. These animals were put in six, 06 blocks with two treatments. The animals were divided in groups: Control group $(n=6)$ each animal received 5 $\mathrm{ml}$ of physiological solution subcutaneously in the left ear, and Treated group $(n=6)$ each animal received $5 \mathrm{ml}$ of moxidectin at $10 \%$ subcutaneously in the right ear. The animals were submitted to andrological examinations weekly, within a period of 60 days after the treatment. The testicular characteristics (consistency and perimeter) and seminal characteristic (motility, strength and morphology) were evaluated. Libido tests were done every fortnight, in five tests all together. The results indicated that there were not significant differences. $(\mathrm{P}>0.05)$ for the testicular consistency, perimeter, progressive motility, spermatic strength, morphology and libido among bulls of the control and treated groups. These results indicated that the treatment with moxidectin at $10 \%$ does not influence negatively on the reproductive characteristics of the bulls.
\end{abstract}

Key words: Bovines. Spermatozoa. Anthelmintic. 


\section{LISTA DE TABELAS}

Página

Tabela 1 - Classificação dos touros e distribuição dos animais em blocos e grupos experimentais. Pirassununga - 2007

Tabela 2 - Média \pm erro padrão em função das semanas para a variável consistência testicular, nota atribuída de 1 a 5 para touros, segundo tratamento com moxidectina 10\%. Pirassununga - 2007.

Tabela 3 - Média \pm erro padrão do perímetro escrotal $(\mathrm{cm})$, semanal para os touros, segundo tratamento com moxidectina 10\%. Pirassununga $-2007$

Tabela 4 - Média \pm erro padrão da motilidade progressiva (\%) para touros semanalmente, segundo tratamento com moxidectina $10 \%$. Pirassununga - 2007

Tabela 5 - Média \pm erro padrão do vigor espermático, em escore de 1 a 5 para touros semanalmente, segundo tratamento com moxidectina 10\%. Pirassununga - 2007

Tabela 6 - Média \pm erro padrão do defeito espermático maior (\%) para touros semanalmente, segundo tratamento com moxidectina $10 \%$. Pirassununga - 2007

Tabela 7 - Média \pm erro padrão do defeito espermático menor $(\%)$ para touros semanalmente, segundo tratamento com moxidectina $10 \%$. Pirassununga - 2007

Tabela 8 - Média \pm erro padrão dos defeitos espermáticos totais (\%) semanalmente para touros, segundo tratamento com moxidectina $10 \%$. Pirassununga - 2007 


\section{LISTA DE FIGURAS}

Página

Figura 1 - Fórmula estrutural da ivermectina ................................................ 39

Figura 2 - $\quad$ Fórmula estrutural da moxidectina .................................................. 39

Figura 3 - Esquema de um canal iônico típico, oscilando entre as conformações aberta e fechada

Figura 4 - $\quad$ Esquema de sinapse química: A, em repouso; B, ativa ..................... 42

Figura 5 - $\quad$ Ilustração esquemática do experimento. Pirassununga - 2007 ........... 53

Figura 6 - Colheita de sêmen com eletroejaculador (A), detalhe da introdução do dispositivo (B) ...................................................................... 57

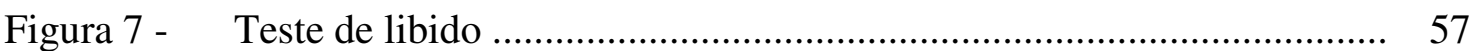




\section{LISTA DE QUADROS}

Página

Quadro 1 - Classificação das características comportamentais apresentadas por touros frente duas fêmeas em estro durante 5 minutos no teste de libido

Quadro 2 - Análise de Variância para delineamento com 2 tratamentos, 6 Blocos, 12 animais e 10 diferentes tempos de amostragem 


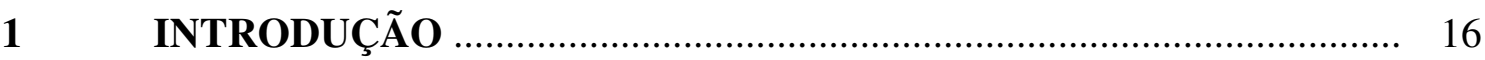

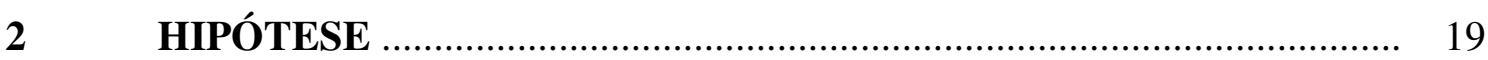

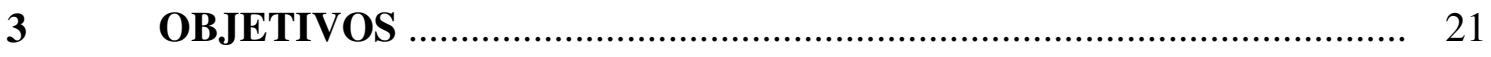

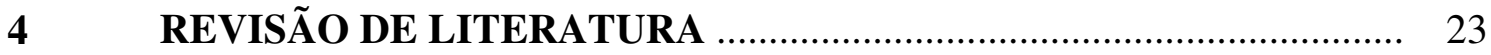

$4.1 \quad$ ESPERMATOGÊNESE ................................................................ 24

4.1.1 Barreira hemato-testicular ............................................................... 28

4.1.2 Controle hormonal da espermatogênese ………….................................. 29

4.2 ESTRUTURA DO ESPERMATOZÓIDE .............................................. 31

4.2.1 Cabeça ……………………....................................................... 31

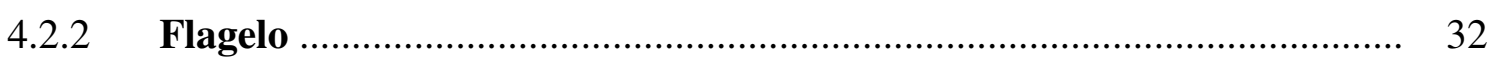

4.3 AVALIAÇÃO DAS CARÂCTERÍSTICAS REPRODUTIVAS DE

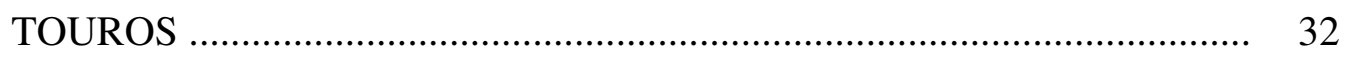

4.3.1 Avaliação do comportamento sexual de touros - Teste de libido.... 33

4.3.2 Avaliação da qualidade do sêmen ............................................................. 33

4.3.3 Motilidade espermática …………………………………………....... 34

4.3.4 Morfologia espermática ..................................................................... 35

4.4 FATORES QUE INFLUENCIAM A QUALIDADE ESPERMÁTICA ...... 35

4.5 INFLUÊNCIAS DO CONTROLE DO PARASITISMO SOBRE A PRODUTIVIDADE EM BOVINOS ...................................................... 36

4.6 NATUREZA QUÍMICA E FARMACOCINÉTICA DA MOXIDECTINA 37

4.6.1 Mecanismo de ação das lactonas macrocíclicas ........................................ 40

4.6.2 Canais iônicos e propriedades elétricas das membranas ……………….. 40

4.6.2.1 Propriedades dos canais iônicos .............................................................. 41

4.6.2.2 Mecanismo de ativação dos canais iônicos controlados por um mediador

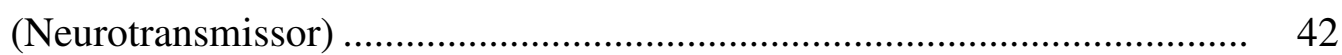

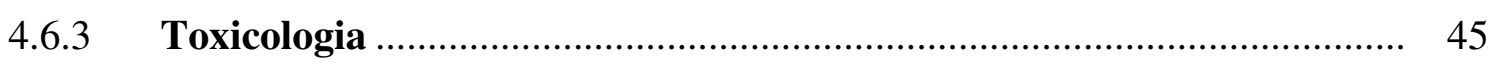

4.7 ATUAÇÃO DO ÁCIDO $\gamma$ - AMINOBUTÍRICO (GABA) SOBRE A LIBERAÇÃO DE LH ........................................................................... 46

4.8 INFLUÊNCIA DA UTILIZAÇÃO DE ANTI-HELMÍNTICOS SOBRE AS CARACTERÍSTICAS REPRODUTIVAS DE MACHOS .................... 46 
5 MATERIAL E MÉTODO 49

5.1 LOCAL E PERÍODO DO EXPERIMENTO ............................................ 50

5.2 ANIMAIS UTILIZADOS ……………………................................... 50

5.3 DISTRIBUIÇÃO DOS ANIMAIS NOS GRUPOS ................................ 50

5.4 DELINEAMENTO EXPERIMENTAL …………................................... 52

5.5 EXAME ANDROLÓGICO ................................................................ 54

5.5.1 Exame clínico reprodutivo …………………………………………..... 54

5.5.2 Colheita e avaliação do ejaculado ……………………………………..... 54

5.5.3 Avaliação da morfologia espermática ………………………………….... 55

5.5.4 Teste de comportamento sexual - libido ………………………………... 55

5.6 ANÁLISE ESTATÍSTICA .................................................................. 57

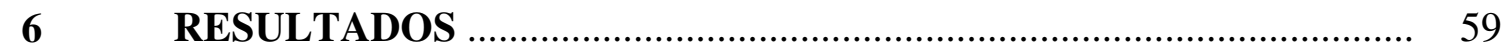

6.1 ÓRGÃOS GENITAIS EXTERNOS ........................................................ 60

6.2 MOTILIDADE PROGRESSIVA E VIGOR ............................................. 62

6.3 MORFOLOGIA ESPERMÁTICA ……………………………………...... 63

6.4 COMPORTAMENTO SEXUAL ………………………………….......... 65

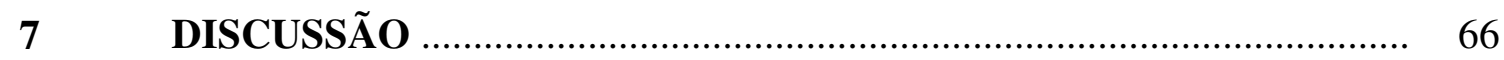

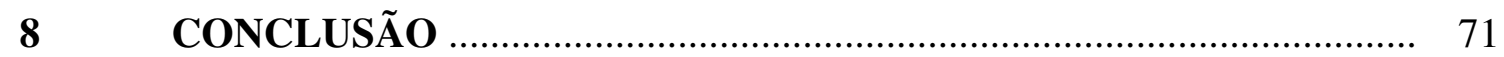

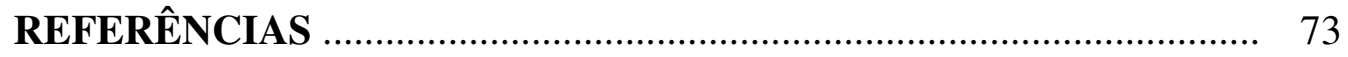




\section{Introdução}




\section{INTRODUÇÃO}

O Brasil é dono do maior rebanho bovino comercial do mundo, com 183 milhões de cabeças, apresentando uma posição privilegiada pela sua diversidade climática e extensão territorial. O segmento bovino representado por seus diversos produtos como carne, couro, pele, calçados e lácteos ocupa um dos principais espaços no agronegócio brasileiro, sendo responsável por bilhões de dólares em exportação (MINISTÉRIO DA AGRICULTURA PECUÁRIA E ABASTECIMENTO, 2006).

A fertilidade é o fator mais importante na determinação da rentabilidade em rebanhos de corte. É essencial que os animais sejam manejados em sistemas que promovam altas taxas de prenhez e precocidade quanto ao início da atividade reprodutiva, uma vez que a performance reprodutiva é altamente correlacionada com as condições nutricionais e de manejo às quais esses animais são submetidos.

A infestação por parasitas internos interfere em todos os aspectos produtivos, diminuindo o ganho de peso e causando influência sobre o início da atividade reprodutiva, exercendo, desse modo, um impacto econômico negativo direto sobre todos os segmentos da indústria de carne bovina.

$\mathrm{O}$ advento do tratamento com anti-helmínticos de largo espectro forneceu um potencial aumento na eficiência reprodutiva, em virtude da melhora no estado geral dos animais. Esse progresso substancial no controle dos helmintos ocorreu essencialmente no final da década de 40, a partir daí, novas drogas têm sido desenvolvidas e, segundo a literatura, com um grau de eficácia e segurança cada vez mais satisfatórios.

Os anti-helmínticos em geral são utilizados de duas maneiras, a saber, terapeuticamente para tratar infecções existentes ou surtos clínicos, ou profilaticamente tendo como base o conhecimento da epidemiologia da doença. A utilização na forma terapêutica deve considerar que a droga de escolha seja efetiva contra os estágios maturos e imaturos dos parasitos, além de atuar de forma bem sucedida na remoção dos mesmos, resultando na suspensão dos sinais clínicos da infecção. Por sua vez, a utilização na forma profilática deve ser economicamente justificável pelo aumento da produção nos animais destinados a esse fim e não deve interferir na imunidade dos 
animais, salientando-se que o uso profilático de forma prolongada deve ser evitado, uma vez que pode estimular o desenvolvimento de resistência.

Os anti-helmínticos mais comumente utilizados incluem os benzimidazóis, os agonistas nicotínicos, o praziquantel, o triclabendazole, e uma classe de antihelmínticos mais recentemente desenvolvida denominada de lactonas macrocíclicas. Esse grupo compreende as ivermectinas e as milbemicinas (moxidectina) droga mais recentemente desenvolvida. Os mesmos são compostos antibióticos que apresentam alta eficácia no controle de infestações de endo e ectoparasitas nas diversas espécies domésticas em doses bastante reduzidas $(\mu \mathrm{g} / \mathrm{kg})$.

A eficácia dos anti-helmínticos no controle de parasitas internos e externos e a associação desses efeitos sobre o ganho de peso e a baixa contagem de ovos de parasitas nas fezes têm sido demonstradas, o que justifica seu uso tanto em criações extensivas quanto em criações de animais elite e doadores de sêmen. Também tem-se avaliado o efeito dos anti-helmínticos sobre características reprodutivas em novilhas. Entretanto, poucos estudos têm sido realizados nos machos, no sentido de avaliar os efeitos do tratamento com esses anti-helmínticos sobre as características reprodutivas e qualidade espermática. 
2 Hipótese 


\section{HIPÓTESE}

No presente trabalho procurou-se testar a hipótese de que a aplicação subcutânea de moxidectina na forma de longa-ação, em sua dose terapêutica $(1 \mathrm{mg} / \mathrm{kg})$, não influencia negativamente a qualidade seminal, as características testiculares e o comportamento reprodutivo de touros. 
3 Objetivos 


\section{OBJETIVOS}

Em face da escassez de estudos no sentido de avaliar a possibilidade de interferência desse composto anti-helmíntico no desempenho reprodutivo de touros, foram objetivos do presente estudo:

1. Avaliar os efeitos do tratamento com moxidectina, na forma de longaação, sobre a motilidade, vigor e características morfológicas de espermatozóides de touros;

2. Verificar a influência da moxidectina sobre a consistência testicular e perímetro escrotal em bovinos;

3. Avaliar o comportamento sexual de touros tratados com moxidectina. 
4 Revisão de Literatura 


\section{REVISÃO DE LITERATURA}

Os parasitas nematóides afetam homens e animais, causando graves prejuízos à saúde pública e consideráveis perdas econômicas. Nesse contexto, a disponibilidade de anti-helmínticos de amplo espectro de ação tem auxiliado na redução de um grande número de perdas em decorrência das infestações parasitárias (KÖHLER, 2001). Entretanto, a abordagem essencial da terapia antiparasitária exige investigações bioquímicas da droga em questão, além do estudo da fisiologia do hospedeiro e do parasita, a fim de se descobrir a existência de diferenças em processos essenciais que irão permitir a inibição seletiva do parasita mas que não comprometa a saúde do hospedeiro (WANG, 2003).

Portanto, para um melhor entendimento dessas questões, é importante ressaltar alguns tópicos relacionados à fisiologia da reprodução masculina, avaliação da qualidade espermática, natureza química do composto anti-helmíntico, bem como as principais influências do mesmo sobre os aspectos relacionados à reprodução.

\subsection{ESPERMATOGÊNESE}

A espermatogênese é um processo de diferenciação celular que ocorre dentro dos túbulos seminíferos, no qual a espermatogônia passa por diversas divisões mitóticas, duas divisões meióticas e numerosas transformações citológicas, levando à formação dos espermatozóides (COUROT; ORTAVANT, 1981).

A duração da espermatogênese na maioria das espécies é semelhante e compreende duas fases distintas que são denominadas espermatocitogênese e espermiogênese (HAFEZ; HAFEZ, 2004).

A espermatocitogênese é processo em que as espermatogônias (células diplóides) passam por mitose e meiose resultando nos espermatócitos primários ou outras células de sua linhagem, enquanto que a espermiogênese é o processo de diferenciação morfológica da espermátide, passando de célula esférica, aflagelada, para uma célula alongada, flagelada, o espermatozóide (PILSWORTH; SETCHELL, 1981; SIU; CHENG, 2004). 
O epitélio germinativo, que circunda os túbulos seminíferos é composto por dois tipos celulares básicos: as células de Sertoli e as células germinativas em diferentes estágios de desenvolvimento. A membrana basal de cada túbulo seminífero consiste de células peritubulares mióides e não mióides que, conjuntamente com as células de Sertoli, contribuem para a formação da lâmina própria (GALDIERI; RICCI, 1998). Junções compactas especializadas são formadas entre as células de Sertoli adjacentes, as quais dividem os túbulos seminíferos em compartimento basal e compartimento adluminal. Essa separação entre compartimentos, efetivamente cria dois ambientes distintos para as espermatogônias do tipo A e as células espermatogênicas em estágios mais avançados de desenvolvimento (PARKS et al., 2003).

As células germinativas primordiais são diplóides e a redução do estado diplóide para o haplóide ocorre durante a meiose. A meiose inclui duas divisões celulares, sendo que os cromossomos são replicados apenas durante a primeira divisão fazendo com que o número de cromossomos seja reduzido à metade (WOLPERT et al., 2000).

Uma divisão inicial da espermatogônia denominada A dará origem a duas células filhas, uma das quais entrará no processo de espermatogênese, enquanto a outra permanecerá como espermatogônia $\mathrm{A}_{0}$. A espermatogônia do tipo $\mathrm{A}_{0}$ progride mitoticamente, originando quatro subtipos de espermatogônias $\left(A_{1}, A_{2}, A_{3}\right.$ e $\left.A_{4}\right)$. No final da divisão mitótica, a espermatogônia, agora denominada do tipo B, dará origem às células filhas, os espermatócitos primários, que sofrerão modificações nucleares progressivas denominadas de pré-leptóteno, leptóteno, zigóteno, paquíteno (inicial e final) e diplóteno (SHARPE, 1994).

Os espermatócitos, então, passam por um outro processo de divisão meiótica ou reducional para formar os próximos estágios de células haplóides chamadas espermátides (CLERMONT, 1972; HULEIHEL; LUNENFELD, 2004).

Cada um dos estágios de prófase meiótica representa diferentes progressões na síntese e replicação de DNA formando duas cromátides idênticas. Essas cromátides homólogas pareadas fundem-se em pontos aleatórios em um processo conhecido como “crossing-over", resultando em uma variedade aleatória de diferentes segmentos de cada cromossomo (WOLPERT et al., 2000). Assim, a prófase da primeira divisão meiótica assegura a heterogeneidade genética e que cada espermatócito secundário e espermátide venham a ser geneticamente únicos (SENGER, 2004). 
A espermatogônia em touros sofre cinco a seis divisões mitóticas (EKSTEDT et al., 1986). Teoricamente, após seis divisões mitóticas, cada espermatogônia do tipo A deveria dar origem a 64 espermátides, entretanto, devido à degeneração, o número de células não aumenta de acordo com os valores teóricos, de modo que 26,7\% das espermatogônias tipo A degeneram quando se diferenciam para o tipo intermediário (YAN, 2000).

Durante o processo de mitose, o número de espermatócitos primários permanece relativamente estável nos estágios de pré-leptóteno, leptóteno, zigóteno e paquíteno, indicando que poucas células sofrem degeneração durante essas fases (JOHNSON, et al., 2000).

Os espermatócitos na fase de pré-leptóteno e leptóteno estão inseridos antes da barreira formada pelas junções compactas inter-células de Sertoli, no compartimento basal. Todas as outras células germinativas meióticas e pós meióticas situam-se no compartimento adluminal e, portanto, fora dessa barreira (GHABRIEL et al., 2002; SIU; CHENG, 2004). As células germinativas do epitélio adluminal são, dessa forma, isoladas, não tendo acesso direto a nutrientes ou hormônios derivados da corrente sangüínea e fluido intersticial, sendo elas, então, dependentes das células de Sertoli para suprir todas as suas necessidades (SHARPE, 1994).

Os vários estágios da transformação da espermátide são divididos em quatro fases denominadas: fase de golgi, fase de capuchão, fase de acrossomo e fase de maturação (BARTH; OKO, 1989; SENGER, 2004; HAFEZ; HAFEZ, 2004).

A fase de Golgi é caracterizada pela primeira fase no desenvolvimento do acrossomo. A espermátide recentemente formada contém uma grande quantidade de aparelho de Golgi altamente desenvolvido, localizado acima do núcleo e que vai dar origem ao acrossomo. Várias pequenas vesículas pró-acrossomais, formadas a partir do aparelho de Golgi, juntam-se para formar uma grande vesícula, contendo um denso grânulo acrossômico situando-se ao lado do núcleo. As pequenas vesículas de Golgi vão sendo continuamente adicionadas, aumentando, assim, o tamanho da vesícula. Os centríolos, concomitantemente, migram do citoplasma para a base do núcleo. O centríolo proximal coloca-se em íntima aposição com o núcleo, formando uma base de sustentação para a fixação da cauda à cabeça. O centríolo distal dá origem ao axonema que é a porção central da cauda do espermatozóide (SENGER, 2004).

$\mathrm{Na}$ fase de capuchão ocorre uma distribuição dos grânulos acrossômicos aderentes sobre a superfície do núcleo da espermátide. Nessa fase, a cauda em 
desenvolvimento formada pelo centríolo distal, projeta-se para além da periferia do citoplasma celular em direção ao lúmen do túbulo seminífero. Durante o desenvolvimento inicial, a cauda já consiste de dois túbulos centrais circundados perifericamente por nove túbulos duplos (JOHNSON, 1991).

A fase de acrossomo é a fase em que ocorrem as maiores modificações no núcleo, no acrossomo e na cauda da espermátide em desenvolvimento. As modificações nucleares incluem condensação da cromatina e mudança na forma esferoidal do núcleo para uma forma achatada e alongada. $\mathrm{O}$ acrossomo, que está firmemente aderido ao núcleo, também se condensa e se alonga para acompanhar a forma do núcleo. Essas modificações na forma do núcleo e no acrossomo parecem ser moldadas pelas células de Sertoli circundantes (MOORE; PERSAUD, 2000). Dentro do citoplasma, microtúbulos se associam para formar uma capa cilíndrica temporária chamada manchete que posteriormente circunda o axonema e origina a capa pós-nuclear. Ocorre também o deslocamento do citoplasma no sentido caudal do núcleo e migração das mitocôndrias que se agrupam ao redor do flagelo, na porção posterior ao núcleo, formando uma bainha que caracteriza a peça intermediária (SENGER, 2004).

A fase final de transformação das espermátides alongadas em células que serão liberadas na luz dos túbulos seminíferos é denominada fase de maturação. Dentro do núcleo, a cromatina é condensada à medida que proteínas transitórias são substituídas por protaminas. Uma bainha fibrosa mais nove fibras subjacentes são formadas ao redor do axonema, cobrindo o axonema desde o colo até o início da peça terminal. Nos estágios finais, a manchete desaparece e a célula de Sertoli dá forma ao citoplasma remanescente. A formação dos corpos residuais completa a maturação final e os espermatozóides estão prontos para a liberação (AMAN; SCHANBACHER, 1983).

A espermiação é compreendida como o processo de liberação dos espermatozóides para a luz dos túbulos seminíferos. Os corpos residuais, pelos quais grupos de espermatozóides estão ligados, permanecem aderidos ao epitélio. Durante a liberação do espermatozóide, a ruptura dessa ligação resulta na formação da gota citoplasmática na região do colo do espermatozóide. As células de Sertoli fagocitam corpos residuais remanescentes e células germinativas em degeneração (SHARPE, 1994). O processo completo de espermatogênese, desde a espermatogônia A até a formação do espermatozóide totalmente diferenciado leva em torno de 54 dias no touro (SENGER, 2004). 
A espermiação pode ser facilmente perturbada, seja por um suporte hormonal inadequado, ou pela exposição a químicos, calor, entre outros fatores deletérios, os quais exercem um efeito adverso ao processo de espermatogênese (SHARPE, 1994).

\subsubsection{Barreira hemato -testicular}

O testículo é dividido em um epitélio seminífero avascular, que compreende cerca de $90 \%$ do volume do testículo e um compartimento intersticial vascularizado composto pelas células de Leydig, vasos linfáticos e sangüíneos, macrófagos e tecido conectivo. Esse último compartimento produz o fluido intersticial que banha as células de Leydig, vasos e a parte externa dos túbulos seminíferos. É através desse fluido que os hormônios e nutrientes são transportados dos vasos para o epitélio seminífero. Assim, o controle de qual substância atravessa o epitélio, da porção basal para a adluminal é realizada pela barreira hemato-testicular (BARTH; OKO, 1989).

Os fatores que influenciam a disponibilidade de hormônios e nutrientes para as células testiculares estão relacionados ao índice de fluxo sangüíneo e permeabilidade dos capilares testiculares e da barreira hemato-testicular (SETCHELL, 1980).

$\mathrm{O}$ conceito de barreira hemato-testicular foi primeiramente desenvolvido na década de 70 , tendo como base a diferença entre a composição dos fluidos e proteínas obtidos da rete testis e lúmen dos túbulos seminíferos e o plasma sangüíneo. Foi demonstrado que a quantidade de potássio e cloreto contida no fluido coletado da rete testis era superior à que foi obtida no plasma sangüíneo. Além disso, a quantidade de proteínas totais do fluido da rete testis foi 20 a 50 vezes menor que no plasma sangüíneo. Havia ainda diferenças na proporção de traços radioativos e corantes que passavam do plasma sangüíneo para o fluido testicular (BART et al., 2002).

A barreira hemato-testicular possui dois componentes principais: as junções compactas entre as células de Sertoli e a barreira de células mióides (JOHNSON et al., 2000; BART et al., 2002). As junções compactas, durante o processo espermatogênico, separam-se e reagrupam-se para acomodar a passagem das células germinativas no estágio de pré-leptóteno e leptóteno (MRUK; CHENG, 2004). A camada de células mióides contráteis está presente na membrana basal ou túnica própria que circunda os 
túbulos seminíferos. Não é bem desenvolvida no touro, o que confere à mesma uma permeabilidade relativamente de pouca importância nessa espécie (HAFEZ; HAFEZ, 2004).

A existência dessa barreira permite uma permeabilidade muito variável, impedindo completamente a entrada de algumas substâncias ou permitindo a total transferência de outras como eletrólitos, nutrientes, hormônios e anticorpos (BARTH; OKO, 1989). Grandes moléculas ou moléculas hidrofílicas são impedidas de entrar. Pequenas moléculas ou moléculas lipofílicas podem entrar no tecido testicular por mecanismos de transporte através da membrana celular (BART et al., 2002). Essa permeabilidade diferencial estabelece um meio adequado para a função espermatogênica dos túbulos seminíferos, regulando a composição do fluido que é secretado no compartimento adluminal (BARTH; OKO, 1989) e protegendo as células espermatogênicas em desenvolvimento das modificações químicas ocorridas no sangue (JUNQUEIRA; CARNEIRO, 1999).

Estudos têm revelado a existência da glicoproteína-P, uma proteína de 170 $\mathrm{kDa}$, que funciona como uma bomba de efluxo transmembrana ATP-dependente, na barreira hemato-testicular (BART et al., 2002; FROMM, 2004; LESPINE et al., 2007). A referida proteína é responsável pela alta tolerância dos mamíferos às lactonas macrocíclicas (PRICHARD, 1997; ROSE et al., 1998; BART et al., 2002; LESPINE et al., 2006, 2007). A glicoproteína-P, juntamente com a proteína 1 associada à resistência multidroga (MRP1) auxilia na manutenção de baixas concentrações intratesticulares de muitos compostos citotóxicos, apesar dos mesmos possuírem moléculas pequenas e lipofílicas. Em ratos, esses compostos não alcançam a mesma concentração nos testículos como alcançam em outros tecidos (BART et al., 2002).

A glicoproteína-P é expressa no endotélio capilar do testículo e também nas células mióides ao redor dos túbulos seminíferos (GHABRIEL et al., 2002). Após difusão passiva do sangue para o interstício testicular a droga pode ser bombeada para fora pela referida proteína (BART et al., 2002).

\subsubsection{Controle hormonal da espermatogênese}


O controle endócrino da espermatogênese é dependente da atividade do eixo hipotálamo-hipófise-testicular que envolve as ações dos hormônios GnRH (Hormônio liberador de gonadotrofinas), FSH (Hormônio Folículo Estimulante), LH (Hormônio Luteinizante) e testosterona (ROSER, 2001).

O FSH desempenha um papel crítico no desencadeamento e evolução do processo espermatogênico durante a puberdade, uma vez que atua principalmente no desenvolvimento dos testículos (RUSSELL et al., 1987). Isso se dá pela estimulação da produção do hormônio peptídico inibina através da ligação do FSH com as células de Sertoli, o qual induz a maturação e crescimento das células dos túbulos seminíferos, além da conversão de andrógenos em estradiol (RUCKEBUSCH et al., 1991; SENGER, 2004).

O eixo hipotalâmico-hipofisário-testicular apresenta um mecanismo de feedback negativo onde os hormônios testiculares, testosterona e inibina, deprimem a secreção de LH e FSH pela adenohipófise (VALE et al., 1994). O feedback negativo da testosterona sobre o GnRH hipotalâmico constitui o regulador primário da secreção das gonadotrofinas, enquanto a inibina bloqueia a secreção principalmente de FSH. A testosterona reduz a freqüência e amplitude dos pulsos de $\mathrm{LH}$ e inibe a secreção de GnRH para o sistema porta hipotalâmico-hipofisário (SOUZA, 2004).

O papel do FSH em mamíferos adultos ainda é controverso (ROSER, 2001). A administração de testosterona em ratos adultos imunizados contra $\mathrm{GnRH}$, mantém a espermatogênese, em termos quantitativos, apesar da ausência de concentrações detectáveis de FSH (AWONIYI et al., 1989). Na maioria dos mamíferos, a testosterona, sozinha, é capaz de manter qualitativamente a espermatogênese completa, enquanto que o FSH influencia a quantidade de espermatozóides produzidos nos estágios pré e pósmeióticos, dependendo da espécie (ZIRKIN et al., 1986).

Apesar da possibilidade de ocorrer espermatogênese sem a presença de FSH (AWONIYI et al., 1989; ZIRKIN et al., 1986), estudos têm demonstrado a necessidade de LH e FSH no processo de divisão ao qual as espermatogônias e os espermatócitos são submetidos durante a espermatogênese (ROSER et al., 2001).

O FSH atuaria, além da divisão, no processo de maturação, capacidade secretória e arranjo do citoesqueleto das células de Sertoli; estímulo à meiose de espermatócitos e talvez uma ação anti-apoptose em espermatogônias e espermatócitos (MCLACHLAN et al., 1996; PARKS et al., 2003). A testosterona, por sua vez, 
promove a adesão das espermátides às células de Sertoli (PARKS et al., 2003) e a ocorrência normal da espermiogênese (SOUZA, 2004).

Os receptores de gonadotrofinas estão restritos às células de Sertoli e de Leydig, já os receptores para testosterona são encontrados também nas células peritubulares. Dessa forma, a maior ação dos andrógenos no desenvolvimento das células germinativas é indireto, via células de Sertoli ou células mióides peritubulares dos túbulos seminíferos (SHARPE, 1994; PARKS et al., 2003).

\subsection{ESTRUTURA DO ESPERMATOZÓIDE}

Os espermatozóides completamente desenvolvidos são células alongadas, consistindo de uma cabeça achatada contendo o núcleo e uma cauda responsável pela motilidade celular. A característica da célula espermática está relacionada à sua atividade funcional que é assegurar a liberação do material genético contido no núcleo do espermatozóide durante o momento da fertilização (CELEGHINI, 2005).

\subsubsection{Cabeça}

A principal característica da cabeça do espermatozóide é o núcleo achatado de forma oval, consistindo de uma massa condensada de DNA, a cromatina, combinada com as protaminas (JOHNSON, 1991). A cabeça do espermatozóide é dividida em duas regiões: a região anterior ou região acrossomal e a região posterior ou região pósacrossomal (FLESCH; GADELLA, 2000).

O acrossomo é derivado do aparelho de Golgi durante os estágios iniciais da espermatogênese e contém enzimas hidrolíticas que são necessárias para a penetração da zona pelúcida do oócito durante o processo de fertilização dentre elas acrosina, fosfatase ácida, arilsulfatase, colagenase, hialuronidase e fosfolipase (EDDY; O`BRIEN, 1994). O segmento equatorial do acrossomo é a parte que, juntamente com a porção anterior da região pós-acrossômica, se funde com a membrana do oócito no início da fertilização (HAFEZ; HAFEZ, 2004). Durante a reação de acrossomo, o 
conteúdo acrossomal é liberado por exocitose mediada por cálcio. As enzimas acrossomais são ativadas e o espermatozóide penetra na zona pelúcida (EDDY; O`BRIEN, 1994).

\subsubsection{Flagelo}

O flagelo espermático é constituído por capitulum, peça intermediária, peça principal e peça terminal (SENGER, 2004). O colo ou capitulum promove o encaixe entre o flagelo e a fossa de implantação localizada na região pós-acrossomal (SETCHELL, 1990). Estendendo-se caudalmente, ao capitulum encontra-se o axonema, composto por dois microtúbulos centrais circundados por nove microtúbulos duplos (JOHNSON, 1991). A peça intermediária estende-se do colo até o final da hélice mitocondrial. Na peça principal, desaparece a hélice mitocondrial, mas há continuidade dos filamentos do axonema e das fibras mais externas presentes na peça conectora, recoberta por uma bainha fibrosa fenestrada (SETCHELL, 1990). A peça terminal consiste apenas dos nove microtúbulos duplos circundando os microtúbulos centrais, recobertos pela membrana plasmática (GARNER; HAFEZ, 1995; SETCHELL, 1990).

\subsection{AVALIAÇÃO DAS CARACTERÍSTICAS REPRODUTIVAS DE TOUROS}

A avaliação das características comportamentais inerentes à reprodução, aliado ao exame das características do ejaculado, pode auxiliar na determinação do potencial de fertilidade de um determinado reprodutor (SALVADOR et al., 2001).

O potencial de fertilidade de um touro ou sua eficiência reprodutiva estão refletidos na sua longevidade no rebanho, mantendo uma adequada taxa de concepção em um dado período de tempo. Os aspectos que compõem esse potencial são determinados pela capacidade do touro de produzir sêmen, determinada pelo volume de massa testicular (avaliação do perímetro escrotal); capacidade de serviço, determinada pelo teste de libido e qualidade do sêmen, avaliada através da motilidade e morfologia espermática (BARTH; OKO, 1989; MCGOWAN et al., 1994). 


\subsubsection{Avaliação do comportamento sexual de touros - Teste de libido}

Libido é definida como a "disposição" e "impetuosidade" de um touro na tentativa de montar e servir uma fêmea, enquanto que a capacidade de cobertura referese à habilidade e competência do touro em executar esse desejo (CHENOWETH, 1981). A capacidade de serviço é a mensuração do número de serviços efetuados sob condições estipuladas, incluindo, assim, aspectos relativos à libido e habilidade de cobertura (CHENOWETH, 1994).

Apesar de a fertilidade ser influenciada por diversos fatores, como acima mencionado, a libido tem uma considerável importância nesse aspecto. Uma vez que existem diferenças nas taxas de prenhez entre touros com alta, média e baixa capacidade de serviço (BLOCKEY, 1978).

Os fatores que influenciam a libido no touro são a idade, que está associada à experiência sexual do touro; a proporção macho x fêmea; o efeito social, ou seja, o papel que um determinado macho exerce na hierarquia do rebanho e o genótipo (CHENOWETH, 1994).

O teste de libido enfoca os seguintes aspectos (CHENOWETH, 1981):

1 - O cálculo do número de vezes que ocorreu cópula e ejaculação quando o touro foi exposto a um estímulo.

2 - A comparação do número de cópulas completas e incompletas em um dado período de tempo.

3 - Observação do tempo decorrido entre a exposição do touro a uma fêmea em estro e a primeira cópula (tempo de reação).

\subsubsection{Avaliação da qualidade do sêmen}

A quantificação do processo espermatogênico é essencial para a avaliação dos efeitos do ambiente, de drogas ou de outros agentes sobre a função testicular e sobre o potencial de fertilidade de machos normais. Também é importante quantificar a produção espermática para se estabelecerem procedimentos eficientes na exploração do potencial genético de reprodutores de excelência (CASTRO; CARDOSO, 2001). 
O sêmen é a suspensão celular líquida contendo os espermatozóides e as secreções dos órgãos acessórios do trato genital masculino. A porção fluida dessa suspensão é conhecida como plasma seminal que, por sua vez, atua como um veículo, estimulando o metabolismo do espermatozóide e fornecendo a energia necessária para o transporte através do útero (MANN, 1975). Os componentes do plasma seminal incluem ácido ascórbico, aminoácidos, peptídeos, proteínas, lipídeos, ácidos graxos, enzimas, além de imunoglobulinas da classe A, hormônios como andrógenos, estrógenos, prostaglandinas, hormônio folículo estimulante, hormônio luteinizante (LH), hormônio do crescimento, insulina, glucagon, prolactina, relaxina e encefalinas (GARNER; HAFEZ, 1995).

Em média, o ejaculado de um touro adulto normal apresenta de 5 a $8 \mathrm{~mL}$, com concentração espermática que varia entre 200 milhões a 2 bilhões de células por $\mathrm{mL}$, sendo 65 a $95 \%$ morfologicamente normais. Para bovinos, o $\mathrm{pH}$ seminal normal se situa entre 6,4 a 7,8 (HOWARD; PACE, 1988).

A complexa migração que envolve as células germinativas da camada basal para a luz do epitélio seminífero freqüentemente ocasiona a liberação de células imaturas no ejaculado. Do mesmo modo, em casos de danos aos túbulos seminíferos, a estrutura do epitélio é comprometida, o que pode resultar também na liberação prematura de um grande número de células germinativas imaturas (JOHANISSON et al., 2000).

\subsubsection{Motilidade espermática}

A determinação da motilidade espermática envolve estimativas subjetivas da viabilidade dos espermatozóides e da qualidade da motilidade. A avaliação dessa característica no sêmen fresco é um indicador do seu desempenho no próprio fluido (HOWARD; PACE, 1988). Em um ejaculado de touro adulto, a motilidade progressiva apresentada deve ser de, no mínimo, 50\% (MCGOWAN et al., 1994). 


\subsubsection{Morfologia espermática}

O estudo da morfologia espermática pode indicar se a função fisiológica dos testículos e epidídimos está normal (BARTH; OKO, 1989).

A estrutura da célula espermática pode ser avaliada por vários métodos, desde a microscopia óptica com utilização de corantes, microscopia de contraste de fase, microscopia de contraste de interferência diferencial até a utilização de sondas fluorescentes (SALVADOR et al., 2001).

A alta freqüência de espermatozóides morfologicamente anormais ou a alta incidência de um único defeito podem reduzir a fertilidade. As anormalidades morfológicas são classificadas de diversas formas, sendo que algumas classificações dividem as alterações de acordo com a região da célula onde a mesma ocorreu, como cabeça, peça intermediária ou cauda. Outras simplesmente dividem os defeitos em primários e secundários, ou defeitos maiores e menores (HOWARD; PACE, 1988).

A classificação das anormalidades espermáticas em defeitos maiores e

menores foi proposta por Blom (1973), inspirado nas idéias de Milanov. Essa classificação foi realizada levando-se em consideração a maior ou menor importância da anormalidade para a fertilidade (BARTH; OKO, 1989).

As avaliações morfológicas também identificam outras células no ejaculado além dos espermatozóides. Essas células podem fornecer um indicativo de infecções, danos ao testículo ou degeneração testicular (AITKEN; BAKER, 1995). A interpretação da morfologia espermática é sempre retrospectiva, uma vez que o processo de espermatogênese, maturação espermática e trânsito através do epidídimo leva algumas semanas para ser concluído (CASTRO; CARDOSO, 2001).

\subsection{FATORES QUE INFLUENCIAM A QUALIDADE ESPERMÁTICA}

Apesar de não serem considerados reprodutores estacionais, os touros estão sujeitos a influências estacionais sobre a reprodução que podem estar associadas com a temperatura ambiental, disponibilidade de alimentos e carga de parasitos (CHENOWETH, 2000; BRITO et al., 2002), idade do touro (MATHENVON et al., 
1998; FUERST-WALTL et al., 2005), além de fatores genéticos e ambientais (MAKULSKA et al., 1993).

A qualidade seminal refere-se aos vários aspectos relacionados à estrutura e viabilidade do espermatozóide, determinada pela motilidade espermática progressiva e morfologia espermática e também às outras características do ejaculado como o $\mathrm{pH}$, concentração espermática e aspecto. A qualidade seminal do touro reflete o estado funcional do epitélio seminífero do testículo e as funções de maturação, transporte e armazenamento do epidídimo (COUTER, 1994).

\subsection{INFLUÊNCIAS DO CONTROLE DO PARASITISMO SOBRE A PRODUTIVIDADE EM BOVINOS}

O controle de parasitas no rebanho apresenta muitos benefícios relacionados à produtividade, incluindo o aumento do ganho de peso, melhora da conversão alimentar, aumento da produção de leite, melhora da performance reprodutiva, qualidade de carcaça, melhora no estado imunológico, podendo reduzir a morbidade e a mortalidade (ZAJAC et al., 1991; HAWKINS, 1993).

O parasitismo gastrointestinal resulta em uma complexa série de alterações orgânicas que variam desde a forma não detectável de enfermidade até o óbito, dependendo do número de fatores incluindo, a carga parasitária, o tipo de parasito presente, a idade, o estado nutricional e outras condições relevantes para a saúde geral do animal (HAWKINS, 1993).

A utilização de anti-helmínticos em bovinos está associada com a melhoria de diferentes aspectos relacionados com a fertilidade. $\mathrm{O}$ aumento do peso corporal em vacas (ZAJAC et al., 1991; LARSON et al., 1995; MEJÍA et al., 1999; LACAUMENGIDO et al., 2000; CLEALE et al., 2004) e o aumento da taxa de prenhez (HOLSTE et al., 1986) estão associados com a eliminação da carga parasitária, ou diminuição dos ovos de parasitas encontrados nas fezes.

Além do efeito sobre o ganho de peso, Mejía et al. (1999) avaliaram a influência do tratamento com ivermectina, desde o nascimento, sobre a idade e peso à puberdade em novilhas da raça Holandesa. Os autores concluíram que as fêmeas que receberam tratamento com ivermectina desde o nascimento, cresceram mais 
rapidamente do que o grupo controle, sendo que a média diária de ganho de peso foi de $0,65 \pm 0,09$ e $0,55 \pm 0,08$ respectivamente $(\mathrm{P}<0,05)$ até 20 semanas de idade. Ainda no mesmo estudo, os autores encontraram que o início da puberdade, determinado pela concentração de progesterona sérica, ocorreu mais cedo $(\mathrm{P}<0,05)$ nas novilhas tratadas do que nas novilhas parasitadas $(30,4 \pm 0,8$ e 33,7 $\pm 1,3$ semanas de idade, respectivamente).

Outros trabalhos correlacionando o tratamento com anti-helmínticos e a melhoria nas características reprodutivas em fêmeas bovinas têm sido executados. Seguindo a mesma linha de pesquisa, Lacau-Mengido e colaboradores, em 2000, estudaram os efeitos do tratamento contínuo à base de ivermectina em novilhas da raça Holandesa sobre a função reprodutiva (produção de FSH, LH, progesterona e estradiol) do nascimento até a puberdade. Os autores observaram que as novilhas tratadas alcançaram a puberdade 3,7 semanas mais cedo do que as novilhas não tratadas. As concentrações séricas de FSH e estradiol não diferiram entre os grupos tratados e parasitados $(\mathrm{P}<0,05)$, no entanto, a concentração de LH no grupo tratado foi maior do que no grupo não tratado, quatro semanas antes do início da puberdade.

\subsection{NATUREZA QUÍMICA E FARMACOCINÉTICA DA MOXIDECTINA}

A moxidectina é uma milbemicina endectocida produzida pela combinação de síntese química e fermentação. É obtida por modificação química do nemadectin, o composto natural produzido pelo Streptomyces cyaneogriseus quando o mesmo é desenvolvido sob condições de cultura controlada (TAKIGUCHI et al., 1980) e é ativa, em doses extremamente baixas, contra uma ampla variedade de nematóides e artrópodes nos estágios maturos e imaturos (EGERTON et al., 1979; LIFSCHITZ et al., 1999).

A estrutura molecular dos dois grupos de compostos avermectina e milbemicina são semelhantes, ambos compartilham uma unidade macrocíclica formada por 16 estruturas (Figura 1), compostas pela união de três grupos estruturais: o grupo hexahidrobenzofurano, um grupo dissacarídeo ao $\mathrm{C}_{13}$ e um anel espiroquetal do $\mathrm{C}_{17}$ a $\mathrm{C}_{28}$ (MCKELLAR; BENCHAOUI, 1996). A milbemicina é o 23-(O-methyloxime) derivativo do nemadectin (Figura 2), portanto, difere estruturalmente da avermectina por não possuir o dissacarídeo $\mathrm{C}_{13}$ substituindo o anel macrolídeo (FORRESTER et al., 
2002) e possui uma cadeia lateral insaturada na posição $C_{25}$ (ZULALIAN et al., 1994; ALVINERIE et al., 1998).

As moléculas endectocidas são substâncias altamente lipofílicas que se dissolvem na maioria dos solventes orgânicos como clorofórmio, metileno, acetona e tolueno (LANUSSE; PRICHARD, 1997). São compostos fotossensíveis e quando expostos à luz ultravioleta sofrem isomerização das duplas ligações 8-9 e 10-11. São ainda relativamente insolúveis em água e caracterizam-se por uma longa persistência no organismo animal (McKELLAR; BENCHAOUI, 1996; LANUSSE et al., 1997; KRAFT et al., 2003).

O depósito da moxidectina no tecido adiposo pode atuar como um reservatório da droga que contribui para a longa persistência dessa molécula na corrente sanguínea e nos diferentes tecidos-alvos (LIFSCHITZ et al., 1999; CRAVEN et al., 2002; CLEALE et al., 2004). Desse modo, a moxidectina quando administrada em animais com boa condição corporal pode apresentar melhor eficácia do que naqueles com pobre condição corporal (CRAVEN et al., 2002b). A meia vida da moxidectina na corrente sanguínea é de três dias, nove dias no músculo, 11 dias no fígado e rim (ZULALIAN et al., 1994), e sua permanência na gordura é de 14 dias, superando o tempo da ivermectina que é de 7 dias (CHIU et al., 1990).

Segundo Lifschitz et al. (1999) a maior via de eliminação da moxidectina é pelas fezes. Os autores, estudando a farmacocinética da referida droga em diferentes tecidos após administração subcutânea em bovinos, detectaram a presença da mesma (> 0,2 ng/g) nas mucosas abomasal e intestinal, no fluido intestinal, pele, pulmão, bílis, nas fezes e no plasma sangüíneo por um período de até 58 dias após a administração. As concentrações nas mucosas abomasal e intestinal e na pele foram maiores do que as detectadas no plasma $(\mathrm{p}<0,01)$. De acordo com os autores, essa permanência da droga nos diferentes tecidos assegura a eficácia da droga contra diversos endo e ectoparasitas em ruminantes.

Cleale et al. (2004) avaliando os efeitos da utilização da moxidectina $10 \%$ na forma de longa-ação por via subcutânea, obtiveram eficácia terapêutica persistente contra parasitas internos e externos em bovinos por um período de até 150 dias. A produção de ovos de parasitas nas fezes dos animais tratados também foi suprimida em até $90 \%$ no decorrer do experimento. 


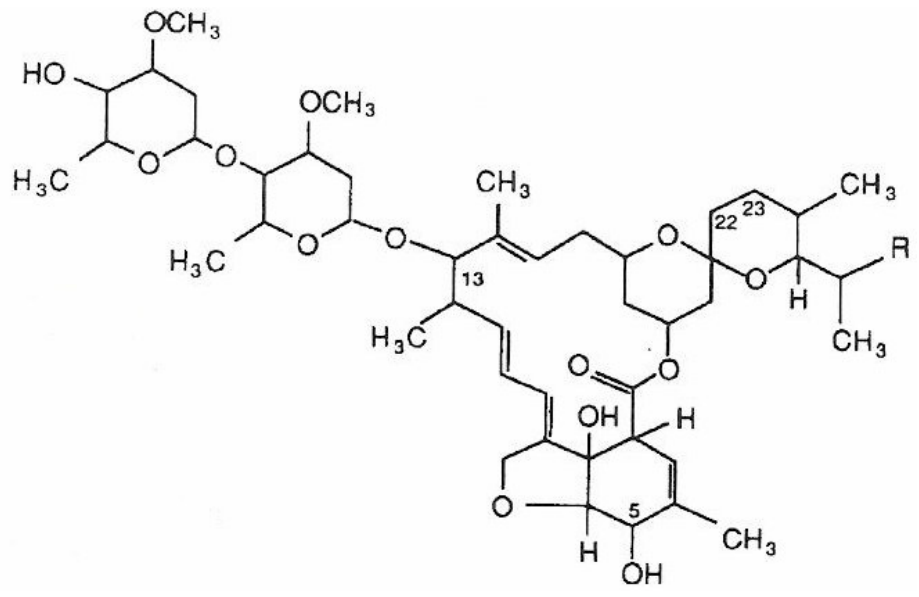

Fonte: Martin et al., 1997

Figura 1 - Fórmula estrutural da ivermectina

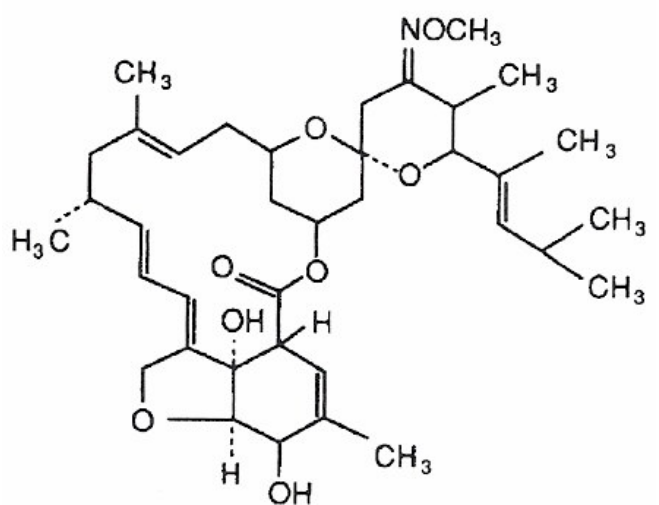

Fonte: Martin et al., 1997

Figura 2 - Fórmula estrutural da moxidectina 


\subsubsection{Mecanismo de ação das lactonas macrocíclicas}

As lactonas macrocíclicas possuem atuação sobre invertebrados possuidores de portais glutamato-cloreto que contém subunidades do tipo $\alpha$ e $\beta$ (BLACKHALL et al., 1998; KÖHLER, 2001; WOLSTENHOLME et al., 2005), com receptores GABAérgicos (CULLY et al., 1996).

Os canais de glutamato cloreto possuidores de receptores GABA desempenham um importante papel na locomoção e na alimentação dos nematóides (MCINTIRE et al., 1993; CULLY et al., 1994) e são encontrados especificamente nas células musculares da faringe e do sistema locomotor de certos invertebrados, incluindo os nematóides (MCKELLAR; BENCHAOUI, 1996; MARTIN et al., 1997).

\subsubsection{Canais iônicos e propriedades elétricas das membranas}

Logo após a introdução da ivermectina, o primeiro composto do grupo das lactonas macrocíclicas disponível no mercado, estudos relacionados ao mecanismo de ação da droga levaram à descoberta dos canais ou portais glutamato-cloreto nos nematóides (KASS et al., 1980; CULLY et al., 1996).

Os canais iônicos formam poros hidrofílicos ou fendas comunicantes através da membrana entre duas células adjacentes, atuando de forma altamente seletiva ao transporte de íons inorgânicos (MARTIN et al., 1998). Os canais iônicos não podem ser acoplados a uma fonte de energia para realizarem o transporte ativo. Dessa forma, o transporte por ele mediado é sempre passivo, permitindo a íons inorgânicos, principalmente $\mathrm{Na}^{+}, \mathrm{K}^{+}, \mathrm{Ca}^{2+}$ ou $\mathrm{Cl}^{+}$, difundir-se rapidamente através da bicamada lipídica, a favor de seus gradientes eletroquímicos (ALBERTS et al., 1997). Esse transporte, apesar de passivo, pode ser controlado e essa capacidade de controle de fluxos iônicos é essencial para muitas funções celulares, principalmente das células nervosas que se especializaram em utilizar os canais iônicos para receber, conduzir e transmitir sinais (MARTIN et al., 1998). 
4.6.2.1 Propriedades dos canais iônicos

\section{SELETIVIDADE IÔNICA}

Os canais iônicos são suficientemente estreitos em alguns locais para forçar os íons a um contato íntimo com as paredes do canal, de modo que apenas os íons do tamanho e da carga apropriados possam passar através da parte mais estreita do canal, isso limita a velocidade de passagem do mesmo (ALBERTS et al., 1997; MARTIN et al., 1998).

\section{FORMA DE CONTROLE DOS CANAIS IÔNICOS}

Os canais iônicos possuem "portões" que não estão continuamente abertos, mas se abrem brevemente e então, novamente, se fecham (ALBERTS et al., 1997) (Figura 3). Na maioria dos casos, os portões se abrem em resposta a um estímulo específico (CULLY et al., 1994). Os principais tipos de estímulos são: mudança de voltagem através da membrana, tensão mecânica ou a ligação a um mediador (neurotransmissor) que pode ser intra ou extracelular (ALBERTS et al., 1997).
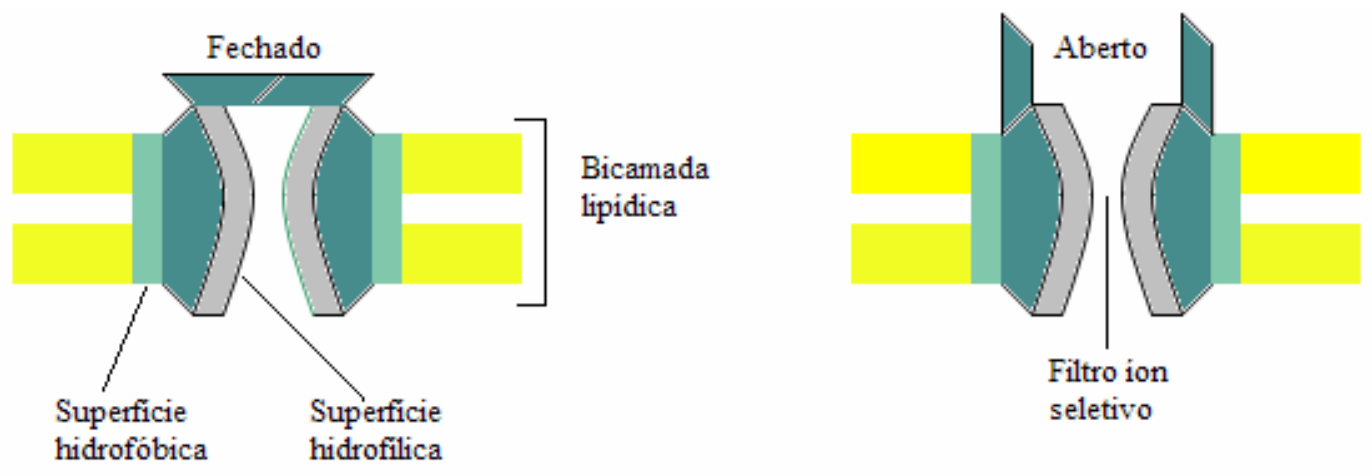

Fonte: Alberts, et al., 1997

Figura 3 - Esquema de um canal iônico típico, oscilando entre as conformações aberta e fechada 
Os canais iônicos são responsáveis pela excitabilidade elétrica das células musculares e medeiam a maioria das formas de sinalização elétrica do sistema nervoso, desempenhando um papel fundamental na manutenção do potencial de membrana celular (CULLY et al., 1996; KÖHLER et al., 2001).

\subsubsection{Mecanismo de ativação dos canais iônicos controlados por um mediador (neurotransmissor)}

O mecanismo de transmissão dos sinais neuronais é indireto, uma vez que as células são eletricamente isoladas umas das outras por uma estreita fenda sináptica. Uma mudança no potencial elétrico da célula pré-sináptica a faz liberar uma pequena molécula sinalizadora, o neurotransmissor, o qual é armazenado em vesículas sinápticas dentro da célula, sendo liberado por exocitose (Figura 4). O neurotransmissor, após ter sido secretado, rapidamente se difunde através da fenda sináptica e provoca uma mudança elétrica na célula pós-sináptica por ligar-se aos canais iônicos (ALBERTS et al., 1997).
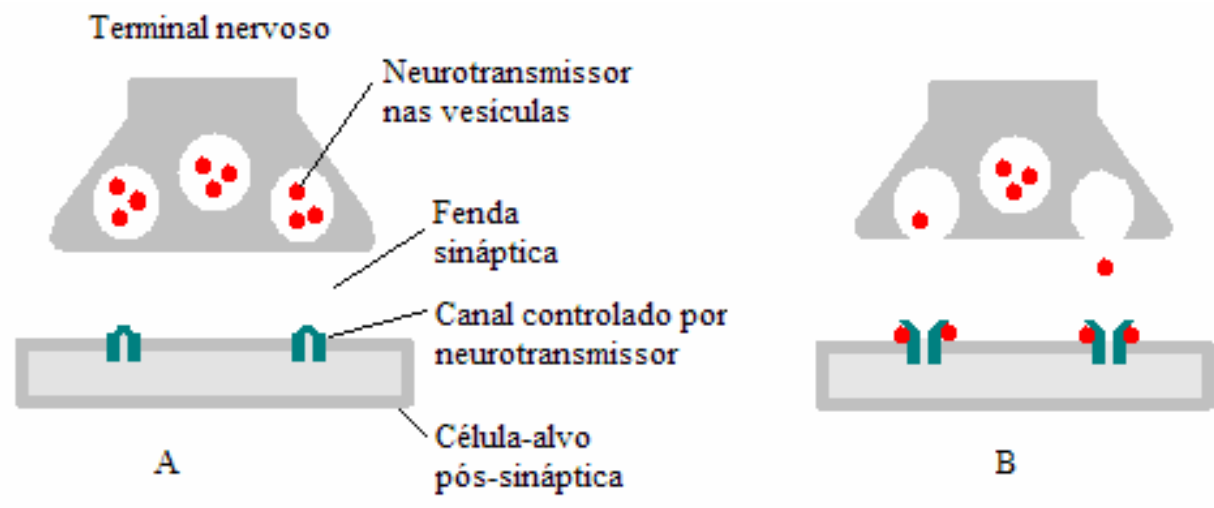

Figura 4 - Esquema de sinapse química: A, em repouso; B, ativa 
Os canais iônicos com portões controlados por neurotransmissor são especializados na conversão rápida de sinais químicos extracelulares em sinais elétricos, e abrem-se transitoriamente em resposta à ligação de moléculas do neurotransmissor, produzindo, desse modo, uma breve mudança na permeabilidade da membrana (MARTIN et al., 1997). Os referidos canais apresentam ainda, algumas características importantes: primeiro, eles possuem um sítio de ligação altamente seletivo para o neurotransmissor que é liberado no terminal pré-sináptico (FORRESTER et al.; 2002); segundo, eles são seletivos quanto ao tipo de íons que os mesmos permitem passar (ALBERTS et al., 1997).

Os neutransmissores podem ser de natureza excitatória ou inibitória (MARTIN et al., 1998). Os neutransmissores excitatórios como a acetilcolina, glutamato e serotonina, abrem canais de cátions, causando um influxo de $\mathrm{Na}^{+}$que despolariza a membrana plasmática na direção do potencial limiar que origina um potencial de ação. Já os neurotransmissores inibitórios, tais como o ácido $\gamma$ aminobutírico (GABA) e glicina, abrem os canais de $\mathrm{Cl}^{-}$, suprimindo assim, as descargas por manter a membrana pós-sináptica polarizada (ALBERTS et al., 1997).

Devido a concentração de $\mathrm{Cl}^{-}$ser muito maior fora da célula, a abertura dos canais de $\mathrm{Cl}^{-}$tenderá a hiperpolarizar a membrana por permitir mais íons cloreto negativamente carregados entrarem na célula (MARTIN, 1997). A abertura dos canais de $\mathrm{Cl}^{-}$torna mais difícil despolarizar a membrana e, portanto, mais difícil excitar a célula (ALBERTS et al., 1997).

Os canais iônicos, que abrem-se em resposta aos neurotransmissores acetilcolina, serotonina, GABA e glicina, contém subunidades $(\alpha, \beta, \gamma$ e $\delta)$ que são estruturalmente similares, sugerindo que eles são correlacionados (KÖHLER, 2001). Esses diferentes tipos de subunidades combinam-se em arranjos diferentes para formar um conjunto muito variado de subtipos distintos de canais, com diferentes afinidades por ligantes, diferentes condutâncias do canal, diferentes velocidades de abertura e fechamento e diferentes sensibilidades a drogas e toxinas (ALBERTS et al., 1997). Essa característica torna possível projetar drogas que atuem em grupos estritamente específicos de células ou sinapses, fazendo com que essas mesmas drogas atuem ligando-se aos canais controlados por esses neurotransmissores (CULLY et al., 1996; BLACKHALL et al., 1998; MARTIN et al., 1998). 
As lactonas macrocíclicas possuem atuação sobre invertebrados possuidores de portais glutamato-cloreto que contém subunidades do tipo $\alpha$ e $\beta$ (KÖHLER, 2001; WOLSTENHOLME et al., 2005), com receptores GABAérgicos (CULLY et al., 1996).

Os canais de glutamato cloreto possuidores de receptores GABA desempenham um importante papel na locomoção e na alimentação dos nematóides (McINTIRE et al., 1993; CULLY et al., 1994) e são encontrados especificamente nas células musculares da faringe e do sistema locomotor de certos invertebrados, incluindo os nematóides (ERDO; LÁSLÓ, 1984; MCKELLAR; BENCHAOUI, 1996; MARTIN et al., 1997).

A função dos receptores GABA é abrir os canais de glutamato-cloreto na junção pós-sináptica (BARRAGRY, 1987). As lactonas macrocíclicas, por sua vez, ligadas à subunidade $\alpha$, atuam como agonistas do glutamato, estimulando a liberação pré-sináptica do GABA, o que causa um aumento do tempo de abertura dos canais, resultando em correntes irreversíveis de íons $\mathrm{Cl}^{-}$seguida por hiperpolarização da membrana celular e paralisia muscular do parasito (ZULALIAN et al., 1994; MARTIN, 1997; BLACKHALL et al., 1998b; KÖHLER, 2001).

Quando da administração de um agente anti-helmíntico em doses terapêuticas, o processo de sucção faríngea, que faz parte do processo de alimentação do parasito, fica comprometido devido à incapacidade do mesmo de fixar-se na mucosa do hospedeiro. A ação da droga causa uma disfunção na atividade de ingestão, com posterior inanição do parasito (CULLY et al., 1996; BLACKHALL et al., 1998a KÖHLER, 2001).

O maior grupo de nematóides refratários ao tratamento com as lactonas macrocíclicas, microfilárias adultas, pode sobreviver ao tratamento com a droga porque nem a movimentação nem a sucção faríngea são requeridas para a sua sobrevivência nos tecidos (CULLY et al., 1996). Entretanto, a longo prazo, ocorre uma redução, por um longo período, na produção de novas larvas (ZULALIAN et al., 1994; MCKELLAR et al., 1998). Com base nisso, pode-se afirmar que esse grupo de drogas possui três efeitos: na locomoção, na sucção faríngea e na reprodução de nematóides (CULLY et al., 1996; MARTIN et al., 1998; KÖHLER, 2001). 


\subsubsection{Toxicologia}

Nos mamíferos, o neurotransmissor GABA localiza-se principalmente no sistema nervoso central e é possível que esse seja o sítio responsável pela toxicidade observada em animais quando as milbemicinas são administradas em doses tóxicas (AFZAL et al., 1994). A razão para a relativa seletividade parasita desses compostos pode estar associada às baixas concentrações necessárias para o estímulo parasitaespecífico dos canais de íons cloreto e à concentração relativamente alta necessária para estimular a liberação de GABA no cérebro do vertebrado (MARTIN, 1997; McKELLAR; BENCHAOUI, 1996).

As lactonas macrocíclicas também têm acesso restrito aos sítios GABA do sistema nervoso central, uma vez que a barreira hemato-cerebral atua como uma barreira parcial para sua distribuição, permitindo somente a passagem de baixas concentrações (MCKELLAR; BENCHAOUI, 1996).

A barreira hemato-cerebral possui muitas características que restringem a troca de moléculas entre a circulação sistêmica e o fluido do compartimento extracelular do cérebro. Essas características incluem a presença de junções celulares muito firmes, ausência de fenestras, reduzida pinocitose e um complexo glicocálice (ROSE et al., 1998).

A glicoproteína-P também contribui como um mecanismo adicional de proteção da barreira hemato-cerebral (PRICHARD, 1997; ROSE et al., 1998; BART et al., 2002; LESPINE et al., 2006), desempenhando um papel essencial na biodisponibilidade das lactonas macrocíclicas no organismo do hospedeiro, bem como nos parasitos-alvo. Por estar presente também no epitélio intestinal e nos canalículos biliares, contribui para a massiva eliminação fecal desse grupo de drogas, modulando a biodisponibilidade da moxidectina nas células e em todo o organismo (BLACKHALL et al., 1998b; LESPINE et al., 2006). 


\subsection{ATUAÇÃO DO ÁCIDO $\gamma$ - AMINOBUTÍRICO (GABA) SOBRE A LIBERAÇÃO} DE LH

Sabe-se que nos nematóides, o ácido $\gamma$ - aminobutírico (GABA) atua como um neurotransmissor periférico primário, cuja regulação na transmissão é um meio efetivo na redução da viabilidade do nematóide (BARRAGRY, 1987; ZULALIAN et al., 1994; MARTIN, 1997; BLACKHALL et al., 1998; KÖHLER, 2001). Nos vertebrados, o GABA é amplamente distribuído no sistema nervoso central, no entanto, altas concentrações de GABA e receptores GABA têm sido reportadas em outros órgãos, incluindo o hipotálamo, hipófise e ovário (ERDO, 1990; WHITTIER et al., 1999).

Apesar do GnRH ser o maior regulador da secreção de LH, diversos outros mediadores exercem modulação direta da função gonadotrópica sobre a hipófise. Dentre esses mediadores estão incluídos opiáceos, ocitocina, vasopressina e o GABA (ANDERSON; MITCHELL, 1986). Os efeitos do GABA, portanto, não estão confinados ao cérebro, mas o referido neurotransmissor atua efetivamente na liberação do LH, sendo que o mecanismo de ação envolvido nesse processo está relacionado a um aumento da concentração de íon $\mathrm{Ca}^{-}$extracelular (VIRMANI et al., 1990).

Segundo Whittier et al. (1999) a ivermectina produz um efeito estimulatório sobre o desenvolvimento folicular e a secreção de LH induzida pelo estradiol em novilhas pré-púberes. Essa estimulação ocorre devido à modulação direta dos receptores de GABA sobre o ovário ou ainda por meio de outros mecanismos como a modulação de secreção de insulina, IGF-1 e/ou Hormônio do crescimento, uma vez que receptores de GABA também são encontrados no sistema hepático e pancreático.

\subsection{INFLUÊNCIA DA UTILIZAÇÃO DE ANTI-HELMÍNTICOS SOBRE AS CARACTERÍSTICAS REPRODUTIVAS DE MACHOS}

Os efeitos adversos do parasitismo sobre a performance reprodutiva de machos têm recebido pouca atenção. Do mesmo modo, os efeitos dos anti-helmínticos 
sobre os aspectos relacionados com a fertilidade em machos têm sido pouco estudados (HAWKINS, 1993).

Dode et al. (1986) compararam os efeitos dos compostos ivermectina e levamisole sobre as características espermáticas de touros Nelore. Foram realizadas oito colheitas de sêmen com intervalos de 15 dias e, segundo os autores, não houve diferença estatística significativa $(\mathrm{P}>0,05)$ entre os dois tratamentos. Os valores obtidos entre os dois tratamentos foram: motilidade $(65,8 \%$ e $70,0 \%)$, concentração espermática $(47,3$ e $\left.61,3 \times 10^{10} / \mathrm{mL}\right)$, defeitos maiores $(6,8 \%$ e $4,8 \%)$, defeitos menores $(2,6 \%$ e $2,7 \%)$ e total de defeitos $(10,1 \%$ e $8,6 \%)$. Esses resultados, segundo os autores, não foram indicativos de efeito prejudicial à qualidade do sêmen.

Com a finalidade de estudar os possíveis efeitos do uso contínuo de ivermectina sobre o ganho de peso, a espermiogênese e a libido de touros, Maciel et al. (1986) utilizaram ivermectina nas doses de $1 \mathrm{~mL} / 50 \mathrm{~kg}$ a cada 30 dias (Grupo 1) e a mesma dosagem a cada 60 dias (Grupo 2) em touros Nelore, sendo o Grupo 3, o grupo controle e que não recebeu nenhum tratamento. A cada 30 dias os animais foram pesados e a contagem de OPG (ovos por grama de fezes) foi realizada. As colheitas de sêmen foram realizadas a cada 15 dias durante os 60 dias que antecederam o início do tratamento; a cada 15 dias, durante 60 dias, no período entre 60 e 120 dias do início do tratamento e, após esse período, a cada 60 dias, até completarem 180 dias da primeira aplicação. Ao final do experimento foram realizados testes de libido e exames histológicos da hipófise, adrenal, testículos, vesícula seminal e próstata. Os resultados obtidos permitiram aos autores concluir que não houve efeito dos tratamentos em relação ao ganho de peso, a contagem de OPG, quadro espermático, libido nem histologia dos órgãos examinados.

Daurio et al. (1987) estudaram os efeitos da repetida utilização da ivermectina $(0,6 \mathrm{mg} / \mathrm{kg})$ sobre a espermatogênese, performance reprodutiva geral, fertilidade e alterações patológicas dos testículos e epidídimos de cães da raça Beagle. Considerando que a média de um ciclo do epitélio seminífero é de 13,6 dias no cão, as colheitas de sêmen foram realizadas a partir do dia 28, a cada 3 dias, até o dia 83 após o início do tratamento, o que compreendeu seis ciclos completos, seguindo assim, segundo os autores, o tempo necessário para o efeito da espermatogênese ser manifestado. Além da avaliação de sêmen, foi realizado teste de fertilidade, ao término do período de colheita de sêmen. As cadelas cobertas foram monitoradas durante a prenhez e foram determinados o peso e o número de fetos vivos e mortos. Os cães, em 
seguida, foram eutanasiados e foi realizada avaliação histológica dos testículos e epidídimos. Os resultados obtidos para a percentagem de espermatozóides móveis e concentração espermática não deferiram entre os grupos $(\mathrm{P}>0,05)$ tratado e não tratado. Também não houve diferença significativa com relação ao tamanho das ninhadas e o número de filhotes nascidos vivos ou mortos. Do mesmo modo que não foram observadas diferenças histológicas significativas entre o grupo tratado com Ivermectina e o grupo controle não tratado, o que levou os autores a concluir que o tratamento com a referida droga na dose de $0,06 \mathrm{mg} / \mathrm{kg}$ não provoca efeitos adversos sobre as características reprodutivas de cães.

Também com o intuito de avaliar o efeito da ivermectina sobre características relacionadqas à reprodução de machos, Janett et al. (2001) utilizaram a referida droga na dose terapêutica $(0,2 \mathrm{mg} / \mathrm{kg})$ e analisaram suas possíveis interferências sobre a qualidade e a congelabilidade de sêmen de garanhões. Foram realizadas colheitas de sêmen uma vez por semana, durante 17 semanas. Após a quarta colheita de sêmen, os animais foram divididos em dois grupos (controle e tratado), onde o grupo tratado recebeu uma dose de $0,2 \mathrm{mg} / \mathrm{kg}$ de ivermectina via oral. A largura testicular foi mensurada uma vez por mês com o auxílio de um paquímetro. O sêmen coletado foi avaliado quanto ao volume, motilidade, concentração, número de espermatozóides totais, morfologia e viabilidade espermáticas, e posteriormente criopreservado. Foram também avaliadas a motilidade e a viabilidade espermática pós-descongelação, utilizando a combinação de sondas fluorescentes, SYBR-14 e Iodeto de Propídio. Sete dias antes e sete dias após a administração da ivermectina, amostras fecais foram coletadas de todos os garanhões para exame parasitológico. Os melhores valores, tanto para o sêmen fresco quanto para o sêmen criopreservado, foram obtidos pelo grupo tratado em todas as características, exceto pelo número de espermatozóides totais e quantidade de defeitos de acrossomo $(\mathrm{P}<0,05)$. As maiores diferenças entre os grupos $(\mathrm{P}<0,0001)$ foram encontradas na motilidade espermática do sêmen fresco e pósdescongelamento, cujos valores foram superiores para o grupo tratado em relação ao grupo controle. Os autores concluem, mediante os resultados obtidos, que a ivermectina pode exercer influência sobre os testículos, epidídimos e glândulas sexuais acessórias ou sobre a hipófise aumentando a liberação de LH. 
5 Material e Método 


\section{MATERIAL E MÉTODO}

\subsection{LOCAL E PERÍODO DO EXPERIMENTO}

O experimento foi realizado no Laboratório de Biotecnologias do Sêmen e Andrologia do Centro de Biotecnologia em Reprodução Animal do Departamento de Reprodução Animal da Faculdade de Medicina Veterinária e Zootecnia da Universidade de São Paulo, localizado no Campus de Pirassununga, SP.

O período experimental estendeu-se de 23 de fevereiro a 07 de maio de 2005, totalizando 10 semanas de experimento.

\subsection{ANIMAIS UTILIZADOS}

Foram utilizados 12 touros da raça Simental, PO (Bos taurus taurus), com idade de $48 \pm 10$ meses. Os animais permaneceram em piquetes contendo capim Brachiaria decumbens e Brachiaria brizantha (variedade Marandu). A alimentação foi constituída por forragem verde (pastejo), sal mineral e água ad libitum e suplementação concentrada, atendendo às recomendações para a categoria, de acordo com o NRC (2001).

\subsection{DISTRIBUIÇÃO DOS ANIMAIS NOS GRUPOS}

Previamente ao início do experimento, os touros foram avaliados quanto à sua capacidade reprodutiva e posteriormente classificados em seis blocos, onde os animais estavam alocados de acordo com os diferentes padrões de qualidade espermática apresentados. Por meio de exame andrológico foram verificadas as condições dos animais quanto às características reprodutivas, sendo estas: consistência testicular (CT), perímetro escrotal (PE), características físicas do sêmen (motilidade, 
vigor, e características morfológicas) e avaliação do comportamento sexual (libido), segundo os critérios do Colégio Brasileiro de Reprodução Animal (CBRA, 1998).

Estando dentro dos padrões mínimos recomendados, os touros foram aprovados para a distribuição nos grupos. Foi usada como referência a média dos valores dos dois ejaculados obtidos antes da aplicação do tratamento, os quais compuseram um índice para cada animal. Este índice foi calculado utilizando-se a seguinte fórmula:

NOTA DO TOURO $=(3 \times$ TDMA $)+(2 \times$ TDME $)+(1 \times I M)$

Fonte: Garcia, 2004

Sendo:

TDMA: Total de defeitos maiores;

TDME: Total de defeitos menores;

IM: Inverso da motilidade.

Para a formação do índice considerou-se o total de defeitos maiores e menores e o inverso da motilidade, deste modo, quanto menor a nota do touro no índice formulado, melhores suas características seminais. Com base nas notas obtidas, os animais foram classificados e subdivididos em seis blocos. A partir de cada bloco, os animais foram distribuídos de forma aleatória em dois grupos de tratamentos experimentais: Grupo Controle (Cont) e Grupo Tratado com moxidectina (Mox), como demonstrado na tabela 1. Cada grupo foi constituído, portanto, de seis animais $(n=6)$. 
Tabela 1 - Classificação dos touros e distribuição dos animais em blocos e grupos experimentais. Pirassununga - 2007

\begin{tabular}{ccccccc}
\hline TOURO & TDMA $^{(\mathbf{1})}$ & TDME $^{(2)}$ & IM $^{(3)}$ & NOTA $^{(4)}$ & BLOCO $^{(5)}$ & GRUPO $^{(6)}$ \\
\hline A137 & 4,2 & 1,2 & 30 & 45,2 & 1 & Cont \\
A99 & 22 & 4 & 30 & 71 & 1 & Mox \\
A144 & 9 & 13,5 & 30 & 84 & 2 & Cont \\
B23 & 34,5 & 3 & 30 & 125 & 2 & Mox \\
A67 & 25,5 & 10,2 & 30 & 127 & 3 & Cont \\
A159 & 24 & 25,5 & 37,5 & 160,5 & 3 & Mox \\
B3 & 12,2 & 3,7 & 30,2 & 73,7 & 4 & Cont \\
A20 & 17,2 & 2,5 & 35 & 91,7 & 4 & Mox \\
B91 & 11,2 & 12,2 & 35 & 93,2 & 5 & Cont \\
A149 & 9,2 & 1,5 & 25 & 55,7 & 5 & Mox \\
B25 & 20 & 1,5 & 27,5 & 90,5 & 6 & Cont \\
B18 & 12,2 & 0,7 & 27,5 & 65,7 & 6 & Mox \\
\hline
\end{tabular}

(1) TDMA: Total de defeitos maiores;

(2) TDME: Total de defeitos menores;

(3) IM: inverso da motilidade;

(4) NOTA: nota atribuída a cada animal, calculada através da fórmula (3 x TDMA) + (2 x TDME) + (1 x IM);

(5) BLOCO: distribuição dos animais em blocos para efeito de análise estatística;

(6) GRUPO: distribuição dos animais em diferentes grupos, para efeito de tratamento experimental (Cont: Grupo Controle; Mox: Grupo tratado com Moxidectina).

\subsection{DELINEAMENTO EXPERIMENTAL}

O experimento foi delineado em blocos ao acaso. Os animais foram divididos em 6 blocos, de acordo com as características reprodutivas observadas no exame andrológico. Efetuado o delineamento experimental os animais foram divididos em dois grupos:

Grupo Controle (Cont/n=6) - Cada animal recebeu $5 \mathrm{~mL}$ de solução fisiológica, via subcutânea, na orelha esquerda. 
Grupo Tratado (Mox/n=6) - Cada animal recebeu $5 \mathrm{~mL}$ de moxidectina a 10\% (formulada pela Fort Dodge Saúde Animal Ltda), via subcutânea, na orelha esquerda.

Os animais foram submetidos a exames andrológicos semanais, sendo o primeiro exame realizado anteriormente à aplicação do tratamento. Um segundo exame no dia da aplicação e outras oito avaliações andrológicas após a aplicação. Foram realizados testes de comportamento sexual (libido) a cada 15 dias, num total de cinco testes, conforme demonstrado na figura 5.

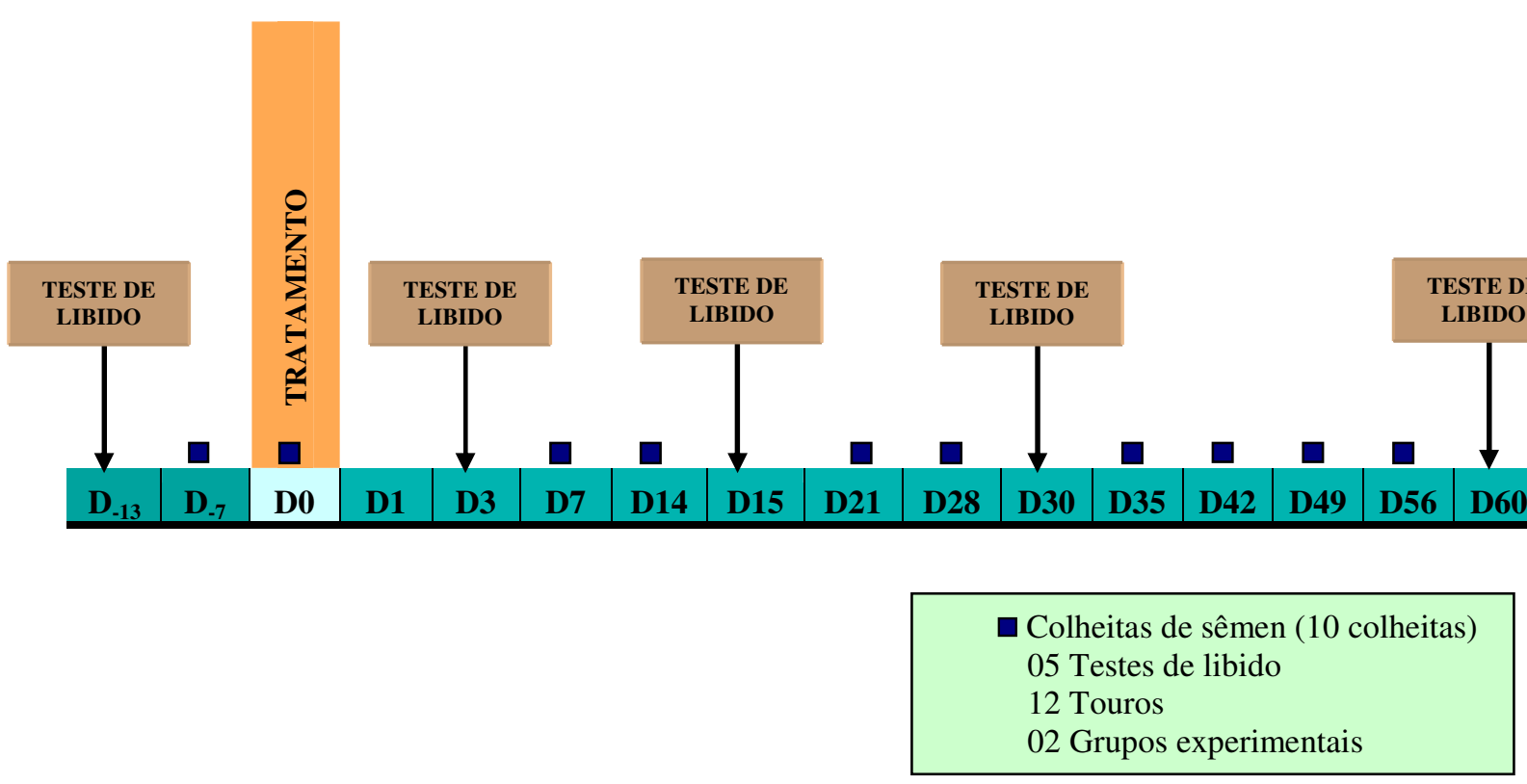

Figura 5 - Ilustração esquemática do experimento. Pirassununga - 2007 


\subsection{EXAME ANDROLÓGICO}

\subsubsection{Exame clínico reprodutivo}

O exame clínico reprodutivo consistiu no exame dos órgãos genitais internos com palpação, via retal, do corpo da próstata, ampolas dos ductos deferentes e glândulas vesiculares; e exame dos órgãos genitais externos: prepúcio, pênis, testículos e epidídimos, observando sua forma, tamanho, posição, simetria e consistência. Para a consistência do testículo atribuiu-se uma nota que variou de 1 a 5 , sendo 1 , consistência flácida, aumentando gradativamente até 5, consistência fibroelástica. Em seguida, realizou-se a mensuração do perímetro escrotal com o uso de uma fita métrica milimetrada, na posição mediana do testículo, no ponto de maior dimensão envolvendo as duas gônadas e a pele escrotal (REFSAL; MATHER, 1977).

\subsubsection{Colheita e avaliação do ejaculado}

As colheitas de sêmen foram realizadas semanalmente, pelo método de eletroejaculação ${ }^{1}$, conforme descrito por Mies Filho (1977) e ilustrado na Figura 6. Após a colheita, o ejaculado foi encaminhado ao laboratório onde foram realizados os exames de motilidade progressiva, vigor e morfologia espermática.

A motilidade progressiva e o vigor foram determinados pela deposição de uma gota de sêmen entre lâmina e lamínula pré-aquecidas a $37^{\circ} \mathrm{C}$. A motilidade progressiva foi determinada pela porcentagem de espermatozóides com movimento progressivo e o vigor foi avaliado com base na qualidade do movimento retilíneoprogressivo e sua velocidade, em uma escala de 1 a 5 . Ambas as avaliações foram realizadas sob microscopia óptica de contraste de fase em aumento de 100x (ZEISS ICS 25).

\footnotetext{
${ }^{1}$ Eletroejaculador Eletrojet ${ }^{\circledR}$, Eletrovet, São Paulo, Brasil.
} 


\subsubsection{Avaliação da morfologia espermática}

Para a análise da morfologia espermática, uma alíquota de $20 \mu \mathrm{L}$ de sêmen foi diluída em $1 \mathrm{~mL}$ de formol salino tamponado e mantida em refrigerador para posterior análise. Cada amostra de sêmen foi avaliada utilizando-se a técnica da câmara úmida, que consiste na deposição de uma gota do sêmen diluído sobre lâmina, coberta por lamínula e analisada em microscópio de contraste de interferência diferencial (Nikon ${ }^{\circledR}$, modelo Eclipse 80i) com aumento de 1000x sob óleo de imersão. A avaliação da morfologia espermática foi procedida com a contagem de 200 espermatozóides, analisando-se as alterações de forma e estrutura e classificando-as em Defeitos Maiores: defeitos de acrossomo (destacado, knobbed, lesado); presença de gota protoplasmática proximal; defeitos de cabeça: (subdesenvolvida, isolada patológica, estreita na base, piriforme, pequena anormal, contorno anormal, pouch formation, cauda enrolada na cabeça); presença de formas teratológicas; defeitos de peça intermediária (fibrilação, fratura total e parcial, edema, pseudogota); defeitos de cauda (fortemente dobrada ou enrolada, dobrada com gota protoplasmática distal anexa); e Defeitos Menores: defeitos de cabeça (delgada, gigante, curta, larga, pequena normal, isolada normal); inserções abaxial, retroaxial e oblíqua; presença de gota protoplasmática distal; defeitos de cauda (enrolada, dobrada).

\subsubsection{Teste de comportamento sexual - libido}

O teste de comportamento sexual escolhido foi o teste de libido, o qual foi realizado uma semana antes da primeira colheita de sêmen e quatro semanas após o tratamento. O teste de libido foi realizado segundo Osborne (1971) e modificado por Chenoweth (1974), no qual cada touro foi colocado em um curral, juntamente com duas vacas em estro durante cinco minutos (Figura 7). Para cada touro, segundo a sua atitude, foi atribuída uma nota, seguindo-se os critérios descritos no quadro 1 . O touro que obteve nota entre 0 e 3 foi tido como questionável; entre 4 a 6 , foi considerado bom; 7 a 8 , muito bom e com nota 9 a 10 , o touro foi classificado como excelente ou superior. 


\begin{tabular}{cl} 
Nota & \multicolumn{1}{c}{ Atitude (s) } \\
\hline 0 & Sem interesse sexual \\
1 & Identificação da fêmea em cio (olfação com reflexo de Fleming) \\
2 & Olfação e perseguição insistente \\
3 & Tentativa de monta sem salto, com mugido, deslocamento e masturbação \\
4 & Tentativa de monta sem salto, com pênis exposto \\
5 & Tentativa de monta com salto, sem pênis exposto \\
6 & Duas ou três tentativas de monta, com salto, sem pênis exposto \\
7 & Tentativas de monta com salto, pênis exposto sem introdução \\
8 & Duas ou três tentativas de monta, com salto e pênis exposto sem introdução \\
9 & Monta com serviço completo \\
10 & Duas ou mais montas com serviços completos \\
\hline
\end{tabular}

Fonte: Chenoweth, 1974

Quadro 1 - Classificação das características comportamentais apresentadas por touros frente duas fêmeas em estro durante 5 minutos no teste de libido 

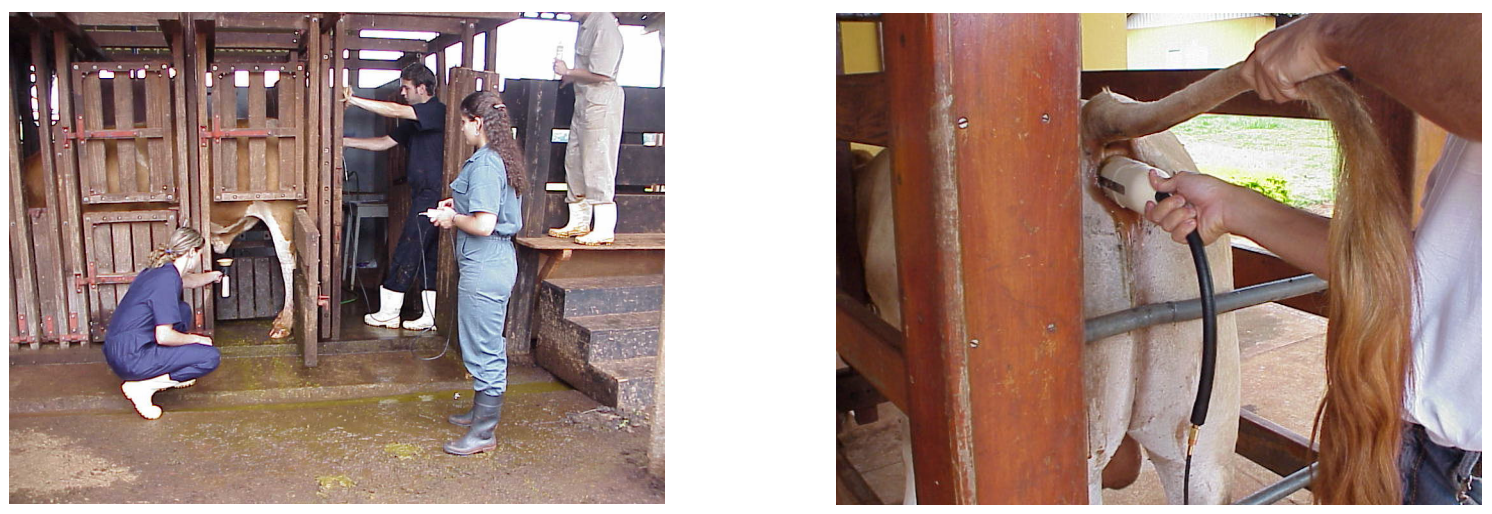

Figura 6 - Colheita de sêmen com eletroejaculador (A), detalhe da introdução do dispositivo (B).

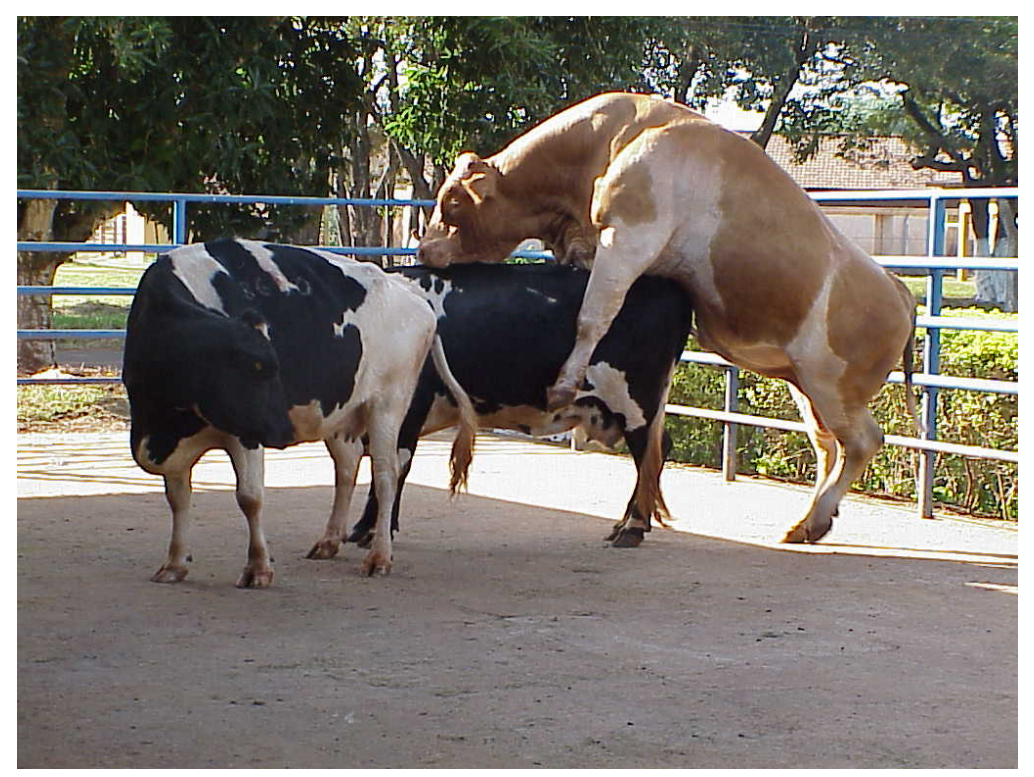

Figura 7 - Teste de libido

\subsection{ANÁLISE ESTATÍSTICA}

Os resultados foram analisados empregando-se o programa Statistical Analysis System (SAS, 1995), sendo verificada a normalidade dos resíduos pelo Teste de Shapiro-Wilk (PROC UNIVARIATE) e as variâncias comparadas pelo Teste de Bartley (OTT, 1983). Os dados defeitos menores e defeitos totais (variáveis 
dependentes) que não atenderam às premissas estatísticas foram submetidos à transformação logarítmica [ $\log (\mathrm{X}+1)]$. Os dados originais ou transformados, quando este último procedimento foi necessário, foram submetidos à Análise de Variância (Quadro 2). A análise estatística foi adicionada ainda do fator medidas repetidas no tempo, referentes aos diversos momentos de amostragem. As probabilidades de interações com o tempo foram determinadas pelo teste de Greenhouse-Geisse, utilizando-se o comando REPEATED gerado pelo procedimento GLM (PROC GLM do SAS). Em todas as análises estatísticas, o nível de significância considerado foi de 5\%.

\begin{tabular}{ll}
\hline CV & GL \\
\hline Tratamento & 1 \\
Animais (tratamento) & 11 \\
Blocos & 5 \\
Tempo & 9 \\
Tempo * tratamento & 9 \\
Resíduo & 84 \\
\hline Total & 119 \\
\hline
\end{tabular}

Quadro 2 - Análise de Variância para delineamento com 2 tratamentos, 6 Blocos, 12 animais e 10 diferentes tempos de amostragem 
6 Resultados 


\section{RESULTADOS}

\section{1 ÓRGÃOS GENITAIS EXTERNOS}

Durante o transcorrer do experimento nenhum dos animais, de ambos os grupos, apresentaram alterações no aparelho genital interno que pudessem ser diagnosticados por palpação retal.

Os dados obtidos no exame dos genitais externos não apresentaram diferença significativa em função do tempo $(\mathrm{P}>0,05)$ para os valores de consistência testicular CT $(\mathrm{P}=0,4519)$, conforme demonstrado na tabela 2. De modo semelhante, os valores obtidos para o perímetro escrotal (PE) não diferiram entre o grupo tratado e o controle $(\mathrm{P}=0,4430)$ em nenhuma das semanas pela qual o experimento transcorreu, como pode ser observado na tabela 2. 
Tabela 2 - Média \pm erro padrão em função das semanas para a variável consistência testicular, nota atribuída de 1 a 5 para touros, segundo tratamento com moxidectina 10\%. Pirassununga - 2007

\begin{tabular}{ccc}
\hline & \multicolumn{2}{c}{ Tratamento } \\
\hline Semanas & Controle & Tratado \\
\hline 1 & $2,75 \pm 0,27$ & $2,67 \pm 0,41$ \\
2 & $2,75 \pm 0,27$ & $2,67 \pm 0,41$ \\
3 & $2,75 \pm 0,27$ & $2,67 \pm 0,26$ \\
4 & $2,58 \pm 0,38$ & $2,50 \pm 0,55$ \\
5 & $2,50 \pm 0,45$ & $2,67 \pm 0,41$ \\
6 & $2,67 \pm 0,26$ & $2,58 \pm 0,38$ \\
7 & $2,67 \pm 0,26$ & $2,75 \pm 0,61$ \\
8 & $2,58 \pm 0,26$ & $2,83 \pm 0,75$ \\
9 & $2,67 \pm 0,26$ & $2,67 \pm 0,52$ \\
10 & $2,75 \pm 0,26$ & $2,67 \pm 0,68$ \\
\hline Média & $2,67 \pm 0,26$ & $2,67 \pm 0,48$ \\
\hline
\end{tabular}

tempo*tratamento-Greenhouse-Geisse $\mathrm{p}=0,4519$

Tabela 3 - Média \pm erro padrão do perímetro escrotal (cm), semanal para os touros, segundo tratamento com moxidectina $10 \%$. Pirassununga 2007

\begin{tabular}{ccc}
\hline & \multicolumn{2}{c}{ Tratamento } \\
\hline Semanas & Controle & Tratado \\
\hline 1 & $42,22 \pm 2,20$ & $43,13 \pm 1,67$ \\
2 & $41,77 \pm 2,29$ & $43,10 \pm 1,52$ \\
3 & $41,98 \pm 1,94$ & $43,07 \pm 1,92$ \\
4 & $42,02 \pm 2,48$ & $43,03 \pm 1,77$ \\
5 & $42,08 \pm 2,55$ & $43,83 \pm 1,64$ \\
6 & $41,25 \pm 2,11$ & $42,72 \pm 1,43$ \\
7 & $41,83 \pm 2,59$ & $42,97 \pm 1,57$ \\
8 & $41,88 \pm 2,58$ & $43,45 \pm 1,66$ \\
9 & $42,15 \pm 2,89$ & $42,98 \pm 1,55$ \\
10 & $41,78 \pm 2,47$ & $43,45 \pm 1,56$ \\
\hline Média & $41,90 \pm 2,25$ & $43,17 \pm 1,54$ \\
\hline
\end{tabular}

tempo*tratamento-Greenhouse-Geisse $\mathrm{p}=0,4430$ 


\subsection{MOTILIDADE PROGRESSIVA E VIGOR}

As variáveis motilidade progressiva e vigor também apresentaram valores semelhantes em ambos os grupos. A motilidade foi em média de 69,70\% e 67,83\% para os grupos controle e tratado, respectivamente, não diferindo significativamente $(\mathrm{P}>0,05)$. Esses valores estão representados na tabela 4 .

Tabela 4 - Média \pm erro padrão da motilidade progressiva $(\%)$ para touros semanalmente, segundo tratamento com moxidectina $10 \%$. Pirassununga - 2007

\begin{tabular}{ccc}
\hline & \multicolumn{2}{c}{ Tratamento } \\
\hline Semanas & Controle & Tratado \\
\hline 1 & $65,00 \pm 5,48$ & $65,00 \pm 4,47$ \\
\hline 2 & $73,33 \pm 2,58$ & $73,00 \pm 6,06$ \\
3 & $71,67 \pm 6,06$ & $68,33 \pm 4,08$ \\
4 & $71,77 \pm 4,08$ & $63,33 \pm 12,52$ \\
\hline 5 & $68,33 \pm 5,16$ & $65,00 \pm 7,07$ \\
6 & $70,00 \pm 5,48$ & $66,66 \pm 4,08$ \\
7 & $71,67 \pm 4,08$ & $72,50 \pm 2,73$ \\
8 & $69,17 \pm 3,76$ & $66,67 \pm 4,08$ \\
9 & $68,33 \pm 4,08$ & $68,33 \pm 5,16$ \\
10 & $67,50 \pm 2,73$ & $69,17 \pm 4,92$ \\
Média & $69,70 \pm 4,77$ & $67,83 \pm 6,40$ \\
\hline
\end{tabular}

tempo*tratamento-Greenhouse-Geisse $\mathrm{p}=0,3138$

Os valores relativos ao vigor espermático também não diferiram entre os tratamentos em função das semanas $(\mathrm{P}=0,1124)$ o que pode ser observado na tabela 5 . 
Tabela 5 - Média \pm erro padrão do vigor espermático, em escore de 1 a 5 para touros semanalmente, segundo tratamento com moxidectina $10 \%$. Pirassununga 2007

\begin{tabular}{ccc}
\hline & \multicolumn{2}{c}{ Tratamento } \\
\hline Semanas & Controle & Tratado \\
\hline 1 & $3,50 \pm 0,45$ & $3,83 \pm 0,26$ \\
2 & $3,40 \pm 0,37$ & $3,75 \pm 0,52$ \\
3 & $3,92 \pm 0,58$ & $3,50 \pm 0,32$ \\
4 & $3,42 \pm 0,38$ & $3,08 \pm 0,66$ \\
5 & $3,83 \pm 0,26$ & $3,50 \pm 0,63$ \\
6 & $3,25 \pm 0,56$ & $3,08 \pm 0,20$ \\
7 & $3,50 \pm 0,45$ & $3,50 \pm 0,32$ \\
8 & $3,67 \pm 0,41$ & $3,23 \pm 0,41$ \\
9 & $3,17 \pm 0,41$ & $3,25 \pm 0,52$ \\
10 & $3,67 \pm 0,26$ & $4,20 \pm 0,51$ \\
\hline Média & $3,53 \pm 0,45$ & $3,49 \pm 0,54$ \\
\hline
\end{tabular}

tempo*tratamento-Greenhouse-Geisse $\mathrm{p}=0,1124$

\subsection{MORFOLOGIA ESPERMÁTICA}

Os valores obtidos para defeitos espermáticos maiores, defeitos menores e os defeitos totais não diferiram significativamente durante a fase experimental, entre o grupo tratado e o controle $(\mathrm{P}>0,05)$, sendo que esses resultados podem ser observados nas tabelas 6,7 e 8 . 
Tabela 6 - Média \pm erro padrão do defeito espermático maior (\%) para touros semanalmente, segundo tratamento com moxidectina $10 \%$. Pirassununga - 2007

\begin{tabular}{ccc}
\hline & \multicolumn{2}{c}{ Tratamento } \\
\hline Semanas & Controle & Tratado \\
\hline 1 & $14,83 \pm 9,69$ & $19,25 \pm 11,44$ \\
2 & $12,58 \pm 7,11$ & $16,83 \pm 8,57$ \\
3 & $11,33 \pm 5,15$ & $18,17 \pm 15,62$ \\
4 & $11,17 \pm 4,73$ & $15,58 \pm 8,94$ \\
5 & $7,75 \pm 3,13$ & $13,67 \pm 10,57$ \\
6 & $11,33 \pm 5,04$ & $11,75 \pm 8,61$ \\
7 & $10,33 \pm 3,87$ & $11,42 \pm 10,23$ \\
8 & $9,10 \pm 1,78$ & $10,83 \pm 7,61$ \\
9 & $12,08 \pm 4,19$ & $11,42 \pm 9,54$ \\
10 & $14,33 \pm 9,31$ & $13,25 \pm 7,41$ \\
\hline Média & $11,53 \pm 5,87$ & $14,22 \pm 9,76$ \\
\hline
\end{tabular}

Tempo*tratamento-Greenhouse-Geisse $\mathrm{p}=0,4703$

Tabela 7 - Média \pm erro padrão do defeito espermático menor (\%) para touros semanalmente, segundo tratamento com moxidectina $10 \%$. Pirassununga - 2007

\begin{tabular}{ccc}
\hline & \multicolumn{2}{c}{ Tratamento } \\
\hline Semanas & Controle & Tratado \\
\hline 1 & $3,92 \pm 3,57$ & $4,17 \pm 3,57$ \\
2 & $9,75 \pm 9,04$ & $8,25 \pm 16,06$ \\
3 & $5,08 \pm 2,44$ & $2,17 \pm 1,40$ \\
4 & $2,83 \pm 2,48$ & $3,83 \pm 4,34$ \\
5 & $10,00 \pm 15,05$ & $2,50 \pm 1,37$ \\
6 & $4,50 \pm 5,39$ & $4,08 \pm 3,71$ \\
7 & $5,08 \pm 5,39$ & $7,58 \pm 12,38$ \\
8 & $2,60 \pm 1,67$ & $6,00 \pm 5,74$ \\
9 & $4,42 \pm 6,72$ & $6,33 \pm 7,13$ \\
10 & $3,50 \pm 2,05$ & $3,83 \pm 2,91$ \\
Média & $5,21 \pm 6,67$ & $4,87 \pm 7,12$ \\
\hline
\end{tabular}

tempo*tratamento-Greenhouse-Geisse $\mathrm{p}=0,5062$ 
Tabela 8 - Média \pm erro padrão dos defeitos espermáticos totais $(\%)$ semanalmente para touros, segundo tratamento com moxidectina $10 \%$. Pirassununga 2007

\begin{tabular}{ccc}
\hline & \multicolumn{2}{c}{ Tratamento } \\
\hline Semanas & Controle & Tratado \\
\hline 1 & $18,75 \pm 10,79$ & $23,41 \pm 13,85$ \\
2 & $22,33 \pm 11,48$ & $25,08 \pm 20,51$ \\
3 & $16,42 \pm 6,47$ & $20,33 \pm 14,99$ \\
4 & $14,00 \pm 5,40$ & $19,42 \pm 12,21$ \\
\hline 5 & $17,75 \pm 16,26$ & $16,17 \pm 11,67$ \\
6 & $15,83 \pm 6,98$ & $15,83 \pm 10,24$ \\
\hline 7 & $15,42 \pm 6,94$ & $19,00 \pm 19,98$ \\
8 & $11,70 \pm 1,15$ & $16,83 \pm 10,29$ \\
\hline & $16,50 \pm 10,02$ & $17,75 \pm 15,45$ \\
10 & $17,83 \pm 9,42$ & $17,08 \pm 9,66$ \\
\hline Média & $16,74 \pm 9,07$ & $19,09 \pm 13,55$ \\
\hline
\end{tabular}

tempo*tratamento-Greenhouse-Geisse $\mathrm{p}=0,7037$

\subsection{COMPORTAMENTO SEXUAL}

As médias das notas atribuídas aos touros para o teste de libido antes da administração

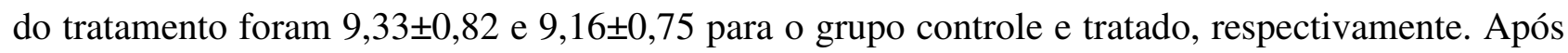

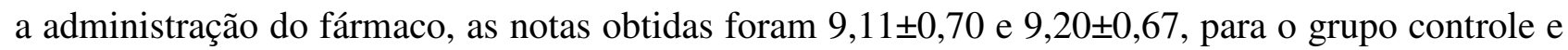
tratado, respectivamente. Os animais foram classificados, portanto, como apresentando libido excelente antes e após a administração da droga. 
7 Discussão 


\section{DISCUSSÃO}

Os resultados obtidos no presente trabalho demonstram que a aplicação de moxidectina LA injetável não influenciou a consistência testicular e o perímetro escrotal em touros, cujos valores foram compatíveis com o mínimo recomendado pelo Colégio Brasileiro de Reprodução Animal (CBRA, 1998) para o perímetro escrotal de touros Bos taurus taurus, com idade acima de 30 meses, que devem ser superiores a $33 \mathrm{~cm}$.

É importante ressaltar que as medidas testiculares avaliadas neste experimento são altamente correlacionadas com a capacidade de produção espermática nos touros. A diminuição no perímetro testicular pode estar associada à presença de compostos citotóxicos, os quais podem ocasionar degeneração do epitélio seminífero, acompanhada da diminuição da consistência testicular devido à perda de massa testicular, refletindo na produção espermática, causando sua diminuição em função da morte das células da linhagem germinativa (CHENOWETH et al., 1984; GIPSON et al., 1985), alterações que não foram observadas pelo tratamento com moxidectina.

Com relação à motilidade progressiva, vigor espermático e morfologia espermática, a saber, defeitos maiores, defeitos menores e defeitos totais, a não observação de diferença estatística $(\mathrm{P}>0,05)$ verificada, também está de acordo com os resultados obtidos por Dode et al. (1986) e Maciel et al. (1986) que avaliaram os possíveis efeitos da utilização da ivermectina sobre as características espermáticas de touros e também não obtiveram diferença estatística $(\mathrm{P}>0,05)$.

Os resultados obtidos para os defeitos maiores, defeitos menores e defeitos totais entre os grupos controle e tratado com moxidectina corroboram aqueles obtidos por Daurio et al. (1987) que, avaliando os possíveis efeitos da utilização da ivermectina sobre a reprodução em cães da raça Beagle, não obtiveram diferença estatística $(P>0,05)$ com relação aos defeitos espermáticos maiores e menores, nem sobre os defeitos espermáticos totais entre os animais dos grupos controle e tratado.

Os resultados obtidos no presente experimento revelam que a moxidectina LA não interfere nas características testiculares, nem no processo espermatogênico, a julgar pela ausência de alterações no quadro espermático dos touros dos grupos controle e tratado. Essa constatação deve-se, provavelmente, à presença da barreira hemato- 
testicular, cuja função normal é proteger o desenvolvimento das células germinativas contra agentes prejudiciais e influências imunológicas (BART et al., 2002).

A barreira hemato-testicular contribui diretamente para uma complexa organização estrutural do testículo criando um ambiente especializado necessário para o desenvolvimento e movimentação das células germinativas (FROMM, 2004). As junções compactas que constituem a barreira hemato-testicular também regulam a passagem de moléculas como nutrientes e resíduos de dentro para fora do epitélio seminífero (MRUK; CHENG, 2004). A função da referida barreira é proteger o delicado processo de meiose das células germinativas da influência deletéria de compostos citotóxicos (BART et al., 2002).

Ainda, as espermatogônias-tronco são muito resistentes à grande variedade de agentes nocivos para o testículo, caso os mesmos consigam atravessar a barreira hemato-testicular, sendo, muitas vezes, o único tipo celular remanescente a danos severos ou prolongados. Acredita-se que a habilidade de sobrevivência dessas células reside no fato de determinada parte da população dessa classe de espermatogônias dividir-se esporadicamente (FRANÇA; RUSSELL, 2001).

A glicoproteína-P, por sua vez, desempenha um papel essencial na biodisponibilidade e distribuição tecidual da droga no organismo do hospedeiro (LESPINE et al., 2006; LESPINE et al., 2007). Localizada na barreira hematotesticular, e também na barreira hemato-cerebral, a referida glicoproteína se liga à citotoxina, removendo-a da membrana e do citoplasma da célula (BLACKHALL, et al., 1998b), desse modo, protege o animal contra a penetração de altas concentrações droga no cérebro, evitando uma subseqüente neurotoxicidade e do mesmo modo no interstício testicular, o que poderia interferir negativamente no processo espermatogênico (BART et al., 2002).

A existência desta glicoproteína poderia impedir a passagem da moxidectina pela barreira hemato-testicular, o que explicaria a não observação de efeitos deletérios sobre a espermatogênese em touros tratados, uma vez que não foi encontrado aumento no percentual de células morfologicamente alteradas neste experimento em touros tratados.

Esses aspectos relacionados à glicoproteína-P também podem explicar a ausência de sinais clínicos de toxicidade às lactonas macrocíclicas como indícios de descarga ocular ou nasal excessiva, tosse, diarréia prostração, ataxia, salivação excessiva, alterações na respiração, tremores musculares ou convulsões, e que também 
não foram relatados em outros estudos (DAURIO et al., 1987; WHITTHIER et al., 1999; JANETT et al., 2001; CLEALE et al., 2004).

Os animais tratados também não exibiram sinais de abscesso no local da injeção da droga, indicado por evidência de exudato, ulceração ou infecção durante a execução deste experimento.

O comportamento sexual dos touros, avaliado pelo teste de libido, também não foi influenciado pelo tratamento no presente experimento $(\mathrm{P}>0,05)$, segundo as respectivas notas atribuídas aos touros do grupo controle e tratado, antes do tratamento $(9,33 \pm 0,82$ e $9,16 \pm 0,75)$ e após o tratamento $(9,11 \pm 0,70$ e 9,20 \pm 067$)$. Observa-se que os touros apresentando libido considerada como excelente antes do experimento, mantiveram essa característica após o tratamento. Resultado esse também verificado por Maciel et al. (1986) que não obtiveram diferença na libido de touros antes e após a utilização de ivermectina.

No presente estudo, foi utilizada moxidectina LA 10\%, injetável, que é caracterizada como sendo uma formulação com base oleosa, de liberação lenta, cuja dose terapêutica recomendada é de $1 \mathrm{mg} / \mathrm{kg}$ de peso. A dose utilizada, portanto, foi cinco vezes a dose aprovada para formulações injetáveis contendo $1 \%$ de moxidectina, cuja indicação para uso é de $0,2 \mathrm{mg} / \mathrm{kg}$ de peso. Apesar dessa grande dose de moxidectina utilizada, nenhum efeito foi observado para nenhuma das características reprodutivas avaliadas.

As colheitas de sêmen foram realizadas, semanalmente, por oito semanas após a administração da droga, sendo a última colheita realizada 56 dias após a administração do tratamento. A duração do período experimental foi estabelecida levando-se em consideração que a espermatogênese nos bovinos leva 54 dias para completar-se (SHARPE, 1994). Desse modo, seguiu-se o tempo necessário para que os possíveis efeitos da droga sobre o processo de formação espermática fossem manifestados.

A ausência de efeitos deletérios nas características reprodutivas avaliadas no presente estudo também está de acordo com os resultados obtidos por Janett et al. (2001), quando da avaliação dos efeitos da ivermectina sobre a qualidade e congelabilidade do sêmen de garanhões. Esses autores ainda especulam que, pelo mecanismo de ação da moxidectina, que atua como agonista do ácido $\gamma$-aminobutírico (GABA), e devido à presença de receptores do referido neurotransmissor também em órgãos periféricos, como o ovário (ERDO, 1990; WHITTIER et al., 1999), é possível que a ivermectina influencie positivamente a fertilidade de machos, uma vez que os 
autores, no seu experimento, obtiveram melhores resultados para a motilidade espermática nos animais que receberam a ivermectina. Os resultados de Jannet et al. (2001) confirmariam aqueles obtidos por Whittier et al. (1999), os quais indicam que a ivermectina produz um efeito estimulatório sobre a dinâmica folicular e a secreção de estradiol induzida pelo LH em novilhas pré-púberes. Seguindo essa mesma linha, outros estudos (LARSON et al., 1995; MEJÍA et al., 1999) também têm relatado a influência positiva da administração das lactonas macrocíclicas na reprodução de fêmeas bovinas.

Nos machos, essa influência ocorreria, ainda segundo Janett et al. (2001), sobre órgãos periféricos, mais precisamente sobre os testículos, epidídimos e glândulas sexuais acessórias, ou sobre a hipófise, induzindo a liberação de LH. 


\section{Conclusão}




\section{CONCLUSÃO}

De acordo com os resultados obtidos e mediante as condições de realização deste experimento, pode-se concluir que:

1. A moxidectina, na forma de longa-ação, em sua dose terapêutica, não provoca efeito negativo sobre a motilidade, vigor e características morfológicas de espermatozóides de touros.

2. A moxidectina não interfere na consistência testicular e perímetro escrotal em bovinos.

3. Touros tratados com moxidectina não apresentam alteração no comportamento sexual. 
Referências 


\section{REFERÊNCIAS}

AFZAL, J.; STOUT, S. DA CUNHA, A.; MILLER, P. Moxidectin: absorption, tissue distribution, excretion and biotransformation of carbon-14-labeled moxidectina in sheep. Journal of Agricultural and Food Chemistry, v. 42, p. 1767-1773, 1994.

AITKEN, R. J.; BAKER, H. W. G. Seminal leukocytes: passengers terrorists or good samaritans? Human Reproduction, v. 10, p. 1736-1739, 1995.

ALBERTS, B.; BRAY, D.; LEWIS, J.; RAFF, M.; ROBERTS, K.; WATSON, J. D. Biologia Molecular da Célula. 3. ed. Porto Alegre: Artes Médicas, 1997, 1294 p.

ALVINERIE, M.; ESCUDERO, E.; SUTRA, J. F.; EECKHOUTTE, C.; GALTIER, P. The pharmacokinetics of moxidectin after oral and subcutaneous administration to sheep. Veterinary Research, v. 29, p. 113-118, 1998.

AMANN, R. P.; SCHANBACHER, B. D. Physiology of male reproduction. Journal of Animal Science, v. 57, p. 380-403, 1983. Supplement, 2.

ANDERSON, R. A.; MITCHELL, R. Effects of gamma-aminobutyric acid agonists acid agonists on the secretion of growth hormone, luteinizing hormone, adrenocorticotrophic hormone and thyroid-stimulating hormone from the rat pituitary gland in vitro. Journal of Endocrinology, v. 108, p. 1-4, 1986.

AWONIYI, C. A.; SANTULLI, R.; SPRANDO, R. L.; EWING, L. L.; ZIRKIN, B. R. Restoration of advanced spermatogenic cells in the experimentally regressed rat testis: quantitative relationship to testosterone concentration within the testis. Endocrinology, v. 124, n. 3, p. 1217-1223, 1989.

AX, R. L.; DALLY, M. R.; DIDION, B. A.; LENZ, R. W.; LOVE, C. C.; VARNER, D. D.; HAFEZ, B.; BELLIN, M. E. Inseminação artificial. In: HAFEZ, B.; HAFEZ, E.S.E. (Ed.).

Reprodução Animal, 7. ed. São Paulo: Manole, 2004. p. 381-394.

BARRAGRY, T. B. A review of the pharmacology and clinical uses of ivermectin. Canadian Veterinary Journal, v. 28, p. 512-517, 1987.

BART, J.; GROEN, H. J. M.; VAN DER GRAAF, W. T. A.; HOLLEMA, H.; HENDRIKSE, N. H.; VAALBURG, W.; SLEIJFER, D. T.; DE VRIES, E. G. E. An oncological view on the bloodtestis barrier. The Lancet Oncology, v. 3, p. 357-363, 2002.

BARTH, A. D.; OKO, R. J. Abnormal morphology of bovine spermatozoa. Ames: Iwoa State University Press, 1989, 285 p.

BLACKHALL, W.; LIU, H-Y.; XU, M.; PRICHARD, R.; BEECH, R. Selection at P-glycoprotein gene in ivermectin and moxidectin-selected strains of Haemonchus contortus. Molecular and Biochemical Parasitology, v. 95, p. 193-201, 1998a. 
BLACKHALL, W.; POULIOT, J. F.; PRICHARD, R. K; BEECH, R. N. Haemonchus contortus: selection at a glutamate-gated chloride channel gene in ivermectin-and moxidectin-selected strains. Experimental Parasitology, v. 190, p.42-48, 1998 b.

BLOCKEY, M. A. B. Development of a serving capacity of bulls on herd fertility. Journal of Animal Science, v. 46, n. 3, p. 589-595, 1978.

BLOM, E. The ultrastructure of some characteristic sperm defects and a proposal for a new classification of the bull spermiogram. Nordisk Veterinaer Medicin, v.25, p.383-391, 1973.

CASTRO, A. C. S.; CARDOSO, F. M. Avaliação dos métodos de quantificação da produção epermática em estudos experimentais em animais domésticos. Cadernos Técnicos de Veterinária e Zootecnia, v. 35, p. 31-40, 2001.

CBRA. COLÉGIO BRASILEIRO DE REPRODUÇÃO ANIMAL. Manual para exame andrológico e avaliação de sêmen animal. 2. ed. Belo Horizonte: CBRA, 1998. 49 p.

CELEGHINI, E. C. C. Efeitos da criopreservação do sêmen bovino sobre as membranas plasmática, acrossomal e mitocondrial e estrutura da cromatina dos espermatozóides utilizando sondas fluorescentes. $186 \mathrm{f}$. Tese (Doutorado em Medicina Veterinária) - Faculdade de Medicina Veterinária e Zootecnia da Universidade de São Paulo, Pirassununga, 2005.

CHENOWETH, P. J. Bull behavior, sex-drive and management. In: FIELD, M. J.; SAND, R. S. (Ed.). Factors affecting calf crop. Ann Arbor: CRC Press, 1994. p. 319-330.

CHENOWETH, P. J. Examination of bulls for libido and mating ability. In: COURSE HELD AT THE UNIVERSITY OF QUEENSLAND VETERINARY SCHOOL, St Lucia: Bulls. 1974, p. 1-5.

CHENOWETH, P. J. Impulso sexual del toro y comportamiento reproductivo. In: Topics in bull fertility, International Veterinary Information Service. Ithaca. New York, 2000. Disponível em: $<$ http:// www.ivis.org >. Acesso em: 20 ago. 2006.

CHENOWETH, P. J.; FARIN, P. W.; MATEOS, E. R.; RUPP, G. P.; PEXTON, J. E. Breeding soundeness and sex drive by breed and age in the beef bulls used for natural mating.

Theriogenology, v. 22, n. 4, p. 341-347, 1984.

CHENOWETH, P. J. Libido and mating behavior in bulls, boars and rams: A review.

Theriogenology, v. 16, n. 2, p. 155-177, 1981.

CHIU, S.; GREEN, M.; BAYLIS, F.; ELINE, D.; ROSEGAY, A.; MERIWETHER, H.; JACOB, T. Absorption, tissue distribution, and excretion of tritium-labelled ivermectin in cattle, sheep, and rat. Journal of Agricultural and Food Chemistry, v. 38, p. 2072-2078, 1990.

CLEALE, R. M.; HART, K. B.; HUTCHENS, D. E.; JOHNSON, E. G.; PAUL, A. J.; SMITH, L. L.; TUCKER, C.;YAZWINSKI, T. A.; DOSCHER, M. E.; GRUBBS, S. T.; WULSTERRADCLIFFE, D. M.; AMODIE, D. M. Effects of subcutaneous injections of a long acting moxidectin formulation in grazing beef cattle on parasite fecal egg reduction and animal weight gain. Veterinary Parasitology, v. 126, p. 325-338, 2004.

CLERMONT, Y. Kinetics of spermatogenesis in mammals, seminiferous epithelium cycle and spermatogonial review. Physiological Reviews, v. 52, n. 1, p. 198-236, 1972. 
COULTER, G. H. Beef bull fertility: Factors affecting seminal quality. In: FIELD, M. J.; SAND, R. S. (Ed.). Factors affecting calf crop. Ann Arbor: CRC Press, 1994. p. 307-317.

COUROT, M.; ORTAVANT, R. Endocrine control of spermatogenesis in the ram. Journal of Reproduction and Fertility, v. 30, p. 47-60, 1981. Supplement.

CRAVEN, J.; BJØRN, H.; HENNESSY, D. R.; FRIIS, C. The effects of body composition on the pharmacokinetics of subcutaneously injected ivermectin and moxidectin in pigs.

Pharmacokinetics, v. 25, p. 227-232, 2002a.

CRAVEN, J.; HENNESSY, D. R.; FRIIS, C. Does the rate deposition influence the pharmacokinetic disposition of subcutaneously administered moxidectina and ivermectin pigs? Journal of Veterinary Pharmacology, v. 25, p. 351-357, 2002b.

CULLY, D. F.; VASSILATIS, D. K.; LIU, K. K.; PARESS, P. S.; VAN DER PLOEG, L. H. T; SCHAEFFER, J. M. Cloning of an ivermectin-sensitive glutamate-gated chloride channel from Chaenorhabdits elegans. Nature, v. 371, p. 707-711, 1994.

CULLY, D. F.; WILKINSON, H.; VASSILATIS, D. K.; ETTER, A.; ARENA, J. P. Molecular biology and electrophysiology of glutamate-gated chloride channels of invertebrates. Parasitology, v. 113, p. 191-200, 1996.

DAURIO, C. P.; GILMAN, M. R.; PULLIAM, J. D.; SEEWARD, R. L. Reproductive evaluation of male beagle and the safety of ivermectin. American Journal of Veterinary Research, v. 48, p. 1755-1760, 1987.

DODE, M. A. N.; SILVA, A. E. F.; BIANCHIN, I.; MATTOS, S. Efeito dos antihelmínticos Ivomec e Ripercol na qualidade espermática (dados preliminares). In: ANAIS CONGRESSO BRASILEIRO DE MEDICINA VETERINÁRIA, 20., 1986, Cuiabá, Brasil. Resumos... 1986, v. 1, p. 191.

EDDY, E. M. O'BRIEN, D. A. The spermatozoon. In: KNOBIL, E.; NEIL, J. D. The physiology of reproduction. New York: Raven Press, 1994. p. 29-77.

EGERTON, J. R.; OSTLIND, D. A.; BLAIR, L. S.; EARY, D. H.; SUHAYDA, D.; CIFELLI, S.; RIEK, R. F.; CAMPELL, W. C. Avermectins, new family of potent anthelmintic agents: efficacy of the $\mathrm{B}_{\mathrm{IA}}$ component. Antimicrobial Agents and Chemotherapy, v. 15, p. 372-378, 1979.

EKSTEDT, E.; SODERQUIST, L.; PLOEN, L. Fine structure of spermatogenesis and Sertoli cells (Epitheliocytus systentans) in bull. Anatomy, Histology and Embryology, v. 15, p. 23-48, 1986.

ERDO, S. R. GABA Outside the CNS. New York: Springer Verlag, 1990.

ERDO, S. R.; LÁSZLÓ, A. H. High specific gamma-aminobutyric acid binding to membrane of the human ovary. Journal of Neurochemistry, v. 42, p. 1464-1467, 1984.

FLESCH, F. M.; GADELLA, B. M. Dynamics of the mammalian sperm membrane in the process of fertilization. Biochimica et Biophysica Acta, v. 1469, p. 197-235, 2000.

FORRESTER, S.; PRICHARD, R. K.; BEECH, R. N. A glutamate-gated chloride channel subunit from Haemonchus contortus: Expression in a mammalian cell line, ligand binding, and modulation of anthelmintic binding y glutamate. Biochemical Pharmacology, v. 63, p. 1061-1068, 2002. 
FRANÇA, L. R.; RUSSELL, L. D. Transplante de espermatogônias: novas perspectivas em reprodução. Cadernos Técnicos de Veterinária e Zootecnia, n. 35, p. 49-59, 2001.

FROMM, M. Importance of P-glycoprotein at blood-tissue barriers. Trends in Pharmacological Sciences, v. 25, n. 8, p. 423-429, 2004.

FUERST-WALTL, B.; SCHWARZENBACHER, H.; PERNER, C.; SÖLKNER, J. Effects of age and environmental factors on semen production and semen quality of Austrian simmental bulls. Animal Reproduction Science, 2005.

GALDIERI, M.; RICCI, G. Characterization of different cell populations isolated from rat testis peritubular cells. Differentiation, v. 63, p. 9-13, 1998.

GARCIA, A. R. Efeitos do estresse térmico testicular e do uso da somatotropina recombinante bovina nas características seminais, integridade de membranas, função mitocondrial e estrutura da cromatina de espermatozóides de touros Simental (Bos taurus taurus). $258 \mathrm{f}$. Tese (Doutorado em Medicina Veterinária) - Faculdade de Medicina Veterinária e Zootecnia, Universidade de São Paulo, Pirassununga, 2004.

GARNER, D. L.; HAFEZ, E. S. E. Espermatozóides. In: HAFEZ, E .R. (Ed.). Reprodução animal. 6. ed. São Paulo: Editora Manole, 1995, p. 187-211.

GHABRIEL, M. N.; LU, J. J.; HERMANIS, G.; ZHU, C.; SETCHELL, B. P. Expression of a blood-brain barrier-sppecific antigen in the reproductive tract of the male rat. Reproduction, $v$. 123, p. 389-397, 2002.

GIPSON, T. A.; VOGHT, D. W.; MASSEY, J. W.; ELLERSIECK, M. R. Associations of scrotal circumference with semen traits in young beef bulls. Theriogenology, v. 24, n. 2 p. 217-225, 1985.

HAFEZ, B.; HAFEZ, E. S. E. Reprodução Animal. 7. ed. São Paulo: Manole, 2004. 513 p.

HAWKINS, J. A. Economics benefits of parasite control in cattle. Veterinary Parasitology, v. 46, p. 159-173, 1993.

HOLSTE, J. E.; WALLACE, D. H.; HUDSON, D. B.; BENZ, G. W.; ERICSON, G. F. Reproductive performance of beef cows treated with ivermectin before calving. Modern Veterinary Practice, v. 67, p. 462-464, 1986.

HOWARD, T. W.; PACE, M. M. Seminal evaluation and artificial examination. In: Fertility and Infertility in Veterinary Practice. 4. ed. London: Baillière Tindall, 1988. p. 39-51.

HULEIHEL, M.; LUNENFELD, E. Regulation of spermatogenesis by paracrine/autocrine testicular factors. Asian Journal of Andrology, v. 6, p. 259-268, 2004.

JANNET, F.; THUN, R.; RYHINER, A.; BURGER, D.; HASSIG, M.; HERTZBERG, H. Influence of eqvalan ${ }^{\circledR}$ (ivermectin) on quality and freezability of stallion semen. Theriogenology, v. 55, p. 785-792, 2001.

JOHANISSON, E.; CAMPANA, A.; LUTHI, R.; AGOSTINI, A. Evaluation of "round cells" in semen analysis: a comparative study. Human Reproduction Update, v. 6, n. 4, p. 404-412, 2000. 
JOHNSON, L. Spermatogenesis. In: CUPPS, P.T. (Ed.) Reproduction in domestic animals. 4. ed. San Diego: Academic Press, 1991. p. 173-219.

JOHNSON, L.; VARNER, D. D.; ROBERTS, M. E.; SMITH, T. L.; KEILLOR, G. E.; SCRUTCHFIELD, W. L. Efficiency of spermatogenesis: a comparative approach. Animal Reproduction Science, v. 60-61, p. 471-480, 2000.

JUNQUEIRA, L. C.; CARNEIRO, J. Aparelho Reprodutor Masculino. In: JUNQUEIRA, L. C.; CARNEIRO, J. Histologia Básica. 9. ed. Rio de Janeiro: Guanabara Koogan, 1999. p. 355-366.

KASS, I. S.; WANG, C. C.; WALROW, J. P.; STRETTON, A. O. W. Avermectin b1A, a paralyzing anthelmintic that affects interneurons and inhibitory motorneurons. Proceedings of the National Academy of Sciences, USA, v .77, p. 6211-6215, 1980.

KÖHLER, P. The biochemical basis of anthelmintc action and resistance. International Journal of Parasitology, v. 31, p. 336-345, 2001.

KRAFT, L. DELAY, R.; SINHA, A. Serum pharmacokinetic characteristics of a moxidectina longacting injectable formulation for cattle. Journal of Veterinary Pharmacology and Therapeutics, v. 26, p. 107-108, 2003. Supplement,. 1.

LACAU-MENGIDO, I. M.; MEJÍA, M. E.; DÍAZ-TORGA, G. S.; GONZALEZ IGLESIAS A.; FORMÍA, N.; LIBERTUN, C.; BECÚ-VILLALOBOS, D. Endocrine studies in ivermectin-treated heifers from birth to puberty. Journal of Animal Science, v. 78, p. 817-824, 2000.

LANUSSE, C.; LIFSCHITZ, A.; VIRKEL, G.; ALVAREZ, L.; SANCHEZ, S.; SUTRA, J.F.; GALTIER, P.; ALVINERIE, M. Comparative plasma disposition kinectics of ivermectin, moxidectin and doramectin in cattle. Journal of Veterinary Pharmacology and Therapeutics, v.20, p.91-99, 1997.

LANUSSE, C.; PRICHARD, R. K. Relationship between pharmacological properties and clinical efficacy of ruminant anthelmintics. Veterinary Parasitology, v. 49, p. 123-158, 1993.

LARSON, R. L.; CORAH, L. H.; SPIRE, M. F.; COCHRAN, R.C. Effect of treatment with ivermectin on reproductive performance of yearling beef heifers. Theriogenology, v. 44, p. 189197, 1995.

LESPINE, A.; DUPUY, J.; ORLOWSKI, S.; NAGY, T.; GLAVINAS, H.; KRAJCSI, P.; ALVINERIE, M. Interaction of ivermectin with multidrug resistance proteins (MRP1, 2 and 3). Chemico-Biological Interactions, v. 159, p. 169-179, 2006.

LESPINE, A.; MARTIN, S.; DUPUY, J.; ROULET, A.; PINEAU, T.; ORLOWSKI, S.; ALVINERIE, M. Interaction of macrocyclic lactones with p-glycoprotein: structure-affinity relationship. European Journal of Pharmaceutical Sciences, v. 30, p. 84-94, 2007.

LIFSCHITZ, A.; VIRKEL, G.; IMPERIALE, F.; SUTRA, J. F.; GALTIER, P.; LANUSSE, C., ALVINERIE, M. Moxidectin in cattle: correlation between plasma and target tissues disposition. Journal of Veterinary Pharmacology and Therapeutics, v. 22, p. 266-273, 1999.

MACIEL, A. S.; LOBREIRO, J. C. T.; ONSELEN V. J. V.; CORTADA, C. N. M.; CASERES, E. N. Estudo do efeito do uso contínuo do Ivermectin sobre a fertilidade de touros da raça Nelore. In: 
ANAIS CONGRESSO BRASILEIRO DE MEDICINA VETERINÁRIA, 20., 1986, Cuiabá, Brasil. Resumos... 1986, v. 1, p. 197.

MAKULSKA, J.; HAGGER, C. H.; KÜNZI, N.; KUPFERSCHMIED, H. U. Genetic and environmental influences on semen traits in A.I. Bulls. Reproduction in domestic animal, v. 28, p. 279-284, 1993.

MANN, T. Biochemistry of semen. In: GREEP, R. O.; ASTWOOD, E. B. (Ed.). Handbook of Physiology. 7. ed. Washington: American of Physiology Society, 1975. p. 461-471.

MARTIN, R. J. Modes of action of anthelmintic drugs. The Veterinary Journal, v. 154, n. 1, p. 11-34, 1997.

MARTIN, R. J.; MURRAY, I.; ROBERTSON, A. P.; BJORN, H.; SANGSTER, N. Anthelmintics and ion-channels: after a puncture, use a patch. International Journal for Parasitology, v. 28, p. 849-862, 1998.

MARTIN, R. J.; ROBERTSON, A. P.; BJORN, H.; SANGSTER, N. Target sites of anthelmintics. Parasitology, v. 114, p. 111-24, 1997.

MATHEVON, M.; BUHR, M. M.; DEKKERS, J. C. Environmental, management, and genetic factors affecting semen production in Holstein bulls. Journal of Dairy Science, v. 81, n. 12, p. 3321-3330, 1998.

MCENTIRE, S. L.; JORGENSEN, E. M., KAPLAN, J.; HORVITZ, H. R. The GABAergic nervous system of Caenorhabditis elegans. Nature, v. 364, p. 337-341, 1993.

MCGOWAN, M.; GALLOWAY, D.; TAYLOR, E.; ENTWISTLE, K.; JOHNSTON, P. The veterinarian examination of bulls. Australian Association of Cattle Veterinarians. 1994. 81 p.

MCKELLAR, Q. A.; BENCHAOUI, H. A. Avermectins and milbemycins. Journal of Veterinary Pharmacology and Terapeutics, v. 19, p. 331-351, 1996.

MCKELLAR, Q. A.; SCOTT, E. W. The benzimidazole anthelmintic agents - a review. Journal of Veterinary Pharmacology and Therapeutics, v. 13, p .223-247, 1998.

MCLACHLAN, R. I.; WREFORD, N. G.; O'DONNELL, L.; KRETSER, D. M.; ROBERTSON, D.M. The endocrine regulation of spermatogenesis: independent roles for testosterone and FSH. Journal of Endocrinology, v. 148, p. 1-9, 1996.

MEJÍA, M. E.; GONZALEZ IGLESIAS, A.; DÍAZ-TORGA, G. S.; VILLAFAÑE, P.; FORMÍA, N.; LIBERTUN, BECÚ-VILLALOBOS, D.; LACAU-MENGIDO, I. M. Effects of continuous ivermectin treatment from birth to puberty on growth and reproduction in dairy heifers. Journal of Animal Science, v. 77, p. 1329-1334, 1999.

MIES FILHO, A. Reprodução dos animais e inseminação artificial. 4. ed. Porto Alegre: Sulina, 1977. p. 517-524.

MINISTÉRIO DA AGRICULTURA, PECUÁRIA E ABASTECIMENTO. Dados Estatísticos. Comércio Exterior Brasileiro. Exportações - Principais produtos. Disponível em: $<$ http://www.agricultura.gov.br/pls/portal/docs/PAGE/MAPA/ESTATÍSTICAS/COMÉRCIO _EXTERIOR_BRASILEIRO>. Acesso em: 09 out. 2006. 
MOORE, K. L.; PERSAUD, T. V. N. Embriologia clínica. 6. ed. Rio de Janeiro: Guanabara Koogan, 2000. p. 15-43.

MRUK, D. D.; CHENG, C. Y. Sertoli-Sertoli and Sertoli-germ cell interactions and their significance in germ cell movement in the seminiferous epithelium during spermatogenesis.

Endocrine Reviews, v. 25, n. 5, p. 747-806, 2004.

NASCIMENTO, E. F.; SANTOS, R. L. Patologia da reprodução dos animais domésticos.2. ed. Rio de Janeiro: Guanabara Koogan, 2003, 137 p.

OMURA, S.; CRUMP, A. The life and times of ivermectin- A success history. Nature Reviews Microbiology, v. 2, p. 984-989, 2004.

OSBORNE, H. G.; WILLIAMS, L. G.; GALLOWAY, D. B. A test for libido and serving ability in beef bulls. Australian Veterinary Journal, v. 47, p. 465-467, 1971.

PARKS, J.E.; LEE, D.R.; HUANG, S.; KAPROTH, M.T. Prospects for spermatogenesis in vitro. Theriogenology, v. 59, p. 73-86, 2003.

PILSWORTH, L. M.; SETCHELL, B. P. Spermatogenic and endocrine functions of the testes of invertebrate and vertebrate animals. In: BURGER, H.; DE KRETSER, D. (Ed.). The testis. 2. ed. New York: Raven Press, 1981. p. 9-38.

PRICHARD, R. How do anthelmintics work? The Veterinary Journal, v. 154, p. 5-7, 1997.

RAE, D. O.; LARSEN, R. E.; WANG, G. T. Safety assessment of moxidectin $1 \%$ injectable on reproductive performance in beef cows. American Journal of Veterinary Research, v. 55, n. 2, p. 251-253, 1994.

ROSE, J. M.; PECKHAM, L. S.; SCISM, J. L.; AUDUS, K. L. Evaluation of the role of pglycoprotein in ivermectin uptake by primary cultures of bovine brain microvessel endothelial. Neurochemical Research, v. 23, n. 2, p. 203-209, 1998.

ROSER, J. F. Endocrine and paracrine control of sperm production in stallions. Animal Reproduction Science, v. 68, p. 139-151, 2001.

RUCKEBUSCH, Y.; PHANEUF, L. P.; DUNLOP, R. Physiology of small and large animals. Philadelphia: B.C. Decker, 1991.

RUSSELL, L. D.; ALGER, L. E.; NEQUIN, L. G. Hormonal control of pubertal spermatogenesis. Endocrinology, v. 120, p. 1615-1632, 1987.

SALVADOR, D. F.; ANDRADE, V. J.; VALE FILHO, V. R. Potencial das proteínas do plasma seminal ou ligadas à membrana espermática como indicadores da fertilidade de touros. Cadernos Técnicos de Veterinária e Zootecnia, n. 35, p. 61-71, 2001.

SAS. STATISTICAL ANALYSIS SYSTEM. SAS user's guide: Statistics. Versão 5. Cary: SAS Institute, 1995.

SENGER, P. L. Pathways to pregnancy and parturition. 2. ed. Washington: State University, Pullman, 2004, 247 p. 
SETCHELL, B. P. The functional significance of the blood-testis barrier. Journal of Andrology, v. 1, p. 3-10, 1980.

SHARPE, R. M. Regulation of spermatogenesis. In: KNOBIL, E.; NEILL, J. D. (Eds.), The Physiology of Reproduction, New York: Raven Press, 1994. p. 1363-1434.

SIU, M. K. Y.; CHENG, C. Y. Dynamic cross-talk between cells and the extracellular matrix in the testis. BioEssays, v. 26, p. 978-992, 2004.

SOUZA, L. W. O. Efeitos da somatotropina recombinante bovina sobre as características espermáticas, concentrações de testosterona e IGF1 no plasma seminal de touros (Bos taurus taurus) submetidos à degeneração testicular. 2004. 183 f. Tese (Doutorado em Medicina Veterinária) - Faculdade de Medicina Veterinária e Zootecnia da Universidade de São Paulo, Pirassununga, 2004.

TAKIGUCHI, Y.; MISHIMA, H.; OKUDA, M.; TERAO, M.; AOKI, A.; FUKUDA, R. Milbemycins, a new family of macrolide antibiotics: fermentation, isolation and physico-chemical properties, Journal of Antibiotics, v. 33, p. 1120-1127, 1980.

VALE, W.; BILEZIKJIAN, L. M.; RIVIER, C. Reproductive and other roles of inhibins and activins. In: KNOBIL, E.; NEILL, J. D. (Ed.). The Physiology of Reproduction. 2. ed. New York: Raven Press, 1994. p. 1861-1871.

VIRMANI, M. A.; STOJILKOVIC, S. S.; CATT, K. J. Stimulation of luteinizing hormone release by $\gamma$-amino butyric acid (GABA) agonist: Mediation by GABA-A type receptors and activation of chloride and voltage-sensitive calcium channels. Endocrinology, v. 126, p. 2499-2505, 1990.

WANG, C. C. Princípios básicos da quimioterapia antiparasitária. In: KATZUNG, B.G.

Farmacologia Básica e Clínica. 8. ed. Rio de Janeiro: Guanabara Koogan, p2003. . 757-767.

WHITTIER, J. C.; WEECH, B. L.; LUCY, M. C.; KEISLER, D. H.; SMITH, M. F.; CORWIN, R. M. Effect of anthelmintic treatment on sexuals maturation in prepubertal beef heifers. Journal of Animal Science, v. 77, p. 736-741, 1999.

WOLPERT, L.; BEDDINGTON, R.; BROCKES, J.; JESSEL, T.; LAWRENCE, P.; MEYEROWITZ, E. Princípios de biologia do desenvolvimento. Porto Alegre: Artmed, 2000. 484 p.

WOLSTENHOLME, A. J.; ROGERS, A. T. Glutamate-gated chloride channels and the mode of action of the avermectin/milbemycin anthelmintics. Parasitology, v. 131, p. 85-95, 2005.

YAN, P. Male Reproductive physiology. In: ZHAO, X. X.; ZHANG, R. C. Recent advances in yak reproduction, Ithaca. New York: International Veterinary Information Service, 2000. Disponível em: <http://www.ivis.org>. Acesso em: 18 ago. 2006.

ZAJAC, A. M.; HANSEN, J. W.; WHITTIER, W. D.; EVERSOLE, D. E. The effect of parasite control on fertility in beef heifers. The Veterinary Parasitology, v. 40, p. 281-291, 1991.

ZIRKIN, B. R.; SANTULLI, R.; AWONIYI, C. A.; EWING, L. L. Maintenance of advanced spermatogenic cells in the adult rat testis: quantitative relationship to testosterone concentration within the testis. Endocrinology, v. 124, p. 3043-3049, 1986. 
ZULALIAN, J.; STOUT, S.; DA CUNHA, A.; GARCES, T.; MILLER, P. Absorption, tissue distribution, metabolism and excretion of moxidectin in cattle. Journal of Agricultural and Food Chemistry, v. 42, p. 381-387, 1994. 